\title{
ARTICLE
}

\section{STREET CRIME, CORPORATE CRIME, AND THE CONTINGENCY OF CRIMINAL LIABILITY}

\author{
DARRYL K. BROWN ${ }^{\dagger}$ \\ INTRODUCTION
}

Theories of culpability and punishment in criminal law seek to explain what conditions are necessary and sufficient for criminal punishment. Under a retributivist view, the defendant's fault or blameworthiness is not only necessary for punishment, but also functions as an affirmative, justifying reason to punish. ${ }^{1}$ Retributivism asserts a crucial role for criminal law's unique ability to express moral condemnation ${ }^{2}$ in addition to more concrete penalties, which civil sanctions often can inflict just as well. ${ }^{3}$ Retributivism implies that when the

† Associate Professor and Alumni Faculty Fellow 2001-2002, Washington and Lee University School of Law. I would like to thank Tony Dillof and Ellen Podgor for insightful readings of earlier drafts. I also thank the Francis Lewis Law Center for research funds that supported my work on this Article.

'An emerging virtue ethics theory of punishment shares with retributivism a retrospective moral judgment of the defendant's conduct, but finds the justification for punishment in a particularized assessment of the offender's circumstances at the time of his conduct; fault in this view is a judgment about the offender's lack of virtue, her flawed practical reasoning, and ultimately her character. See Kyron Huigens, The Dead Eud of Detereure, and Beyond, 41 WM. \& MARY L. REV. 943, 948, 1016-31 (2000) (explaining the features of a virtue ethics theory of punishment).

"St' Henry M. Hart, Jr., The Aims of the Criminal Law, 23 LAW \& CONTEMP. ProBS. $401,40+06$ (1958) (stating that the distinction between civil and criminal law is the latter's power of moral condemnation); Gerard E. Lynch, The Role of Criminal Law in Psliring Carporate Misconduct, LAW \& CONTEMP. PROBS., Summer \& Autumn 1997, at 23, 46 (contending that criminal punishment expresses moral disapproval even if the offender is prepared to pay civil fines and restitution); Paul $\mathrm{H}$. Robinson, Foreword: The Criminal-Civil Distinction and Dangerous Blameless Offenders, $83 \mathrm{~J}$. CRIM. L. \& CRIMINOLOGY $693,707-08$ (1993) (explaining the effectiveness of moral condemnation).

Ser Lynch, supra note 2, at 44 (stating that civil sanctions are sometimes as severe as criminal ones and that "there are many situations in which various civil or administrative remedies may provide a more significant deterrent than criminal punishments"); Kenneth Mann, Punitive Civil Sanctions: The Middleground Between Criminal and Civil Law, I01 YalE L.J. 1795, 1863 (1992) (urging the use of punitive civil sanctions 
offender's conduct meets certain criteria, criminal punishment is not only justified but necessary; in fact, the state has a duty to pursue it. Deterrence, on the other hand, has no role for judgment of an offender's fault or culpability except to the extent that expressing such judgments furthers the deterrent effect of punishment. . Deterrence theory, strictly conceived, does not look retrospectively at an offender's conduct for justification; its view is prospective, justifying a sanction as a means to reduce future wrongdoing.

Even when retributivism or deterrence offers affirmative, justifying reasons to punish offenders, however, in practice we seldom use criminal law to address such wrongdoing. Many considerations affect whether an offender will be charged and convicted beyond whether his conduct accords with the elements of a crime or defense. One aspect of this broader assessment is the jury judgment, which can assess an actor's particular circumstances to determine whether her actions are blameworthy or not. But this process of assessment also occurs at the initial stages of enforcement, when the police and prosecutors decide to arrest and charge, and it is of even broader scope there. The assessment at that stage looks not only at the circumstances around the actor's conduct, but also takes account of a range of consequentialist concerns and practical considerations, such as management of limited resources. Further, such judgments are colored by social perspectives that help distinguish between otherwise similar instances of conduct. $^{5}$ This broad range of criteria explains how the government answers the routine question that permeates criminal practice: when an offender has violated the law and a jury would convict her, on what grounds can the state decline to prosecute? Widespread declination is not fully explained by the common rationale of managing limited resources nor by the marginality of some criminal conduct, such as a first offense or causing minimal harm, ${ }^{6}$ because the state sometimes

for deterrence of "petty and middle-range crimes, regulatory and administrative offenses," and some "victimless" crimes).

* Paul H. Robinson \& John M. Darley, The Utility of Desert, 91 Nw. U. L. REV. 453, 488 (1997) (arguing that the law's moral credibility affects compliance, so the law should accord with the public's moral sensibilities to maximize its deterrent function).

${ }^{5}$ A punch in the nose is an easy case of battery, but when done by a husband to his wife, it has long been treated differently than the same act among strangers. For an excellent study exploring how social biases affect the provocation defense to homicide, see Victoria Nourse, Passion's Progress: Modern Law Reform and the Provocation Defense, 106 YALE L.J. 1331 (1997). For sources on domestic violence prosecution policy, see the discussion in infra Part V.C.2.

${ }^{6}$ For a brief account suggesting some bases other than resources for prosecutorial discretion, see Lynch, supra note 2, at 61-63. 
employs extensive civil remedies for serious wrongdoing covered by criminal statutes that is both intentional and imposes substantial harm. ${ }^{7}$

To describe the actual working of criminal justice practice we need to uncover the criteria, beyond the legal elements, for imposing criminal culpability. Judgments of culpability are contingent not only upon the blameworthiness of an offender's acts, but also upon the perceived efficacy of criminal sanctions as a deterrent. Those assessments, in turn, depend on the alternatives to criminal law-public and private civil law, such as tort law or administrative regulation, as well as other social policy options, such as nonlegal crime prevention strategies like community youth programs and good corporate citizen campaigns." Further, use of criminal law hinges on the social costs of both crime and punishment. Finally, blameworthiness itself is not only weighed against these consequentialist concerns, but shaped by them.

Criminal law's expressive and retributive functions sometimes conflict because punitive approaches alienate offenders, reduce cooperation toward compliance, and may damage the legitimacy of law that is important for deterrence. Even when morally justified, retributivist sanctions can harm prevention efforts and reduce voluntary compliance. Faced with that irony, we sometimes decide to forgo prosecution of offenders for whom we have affirmative, justifying reasons to punish.

This Article makes three broad points. The first is as much conceptual as practical: retributivist and deterrent motives sometimes conflict. Determinations of criminal culpability are contingent on the criminal law's civil alternatives and on its utilitarian costs and benefits. The second is a political and policy point: this conflict is mediated inconsistently, so that criminal liability is distributed more unevenly among white-collar or corporate offenders than it is among street offenders. This is not because of hard distinctions in those realms-different sorts of offenders, crimes, and possible remedies-but because of how we have developed, or failed to develop, civil alternatives to criminal law in each sector and the ideological lens through which we make those alternatives appealing. Corporate and white-collar crime prosecution differs from street crime prosecution because of its different mix of retributive and deterrence concerns, which leads corpo-

${ }^{7}$ Se infra notes $117-31$ and accompanying text (discussing health care fraud and environmental statutes).

"On good corporate citizen campaigns, see William S. Laufer, Corporate Liability, Risk Shifting, and the Paradox of Compliance, 52 VAND. L. REv. 1343, 1382-93 (1999). 
rate crime policy to take greater advantage of our knowledge of how social norms interact with law, of the social costs that accompany punishment, and of the alternatives to criminal law. Criminal law is a comparatively minor tool for addressing white-collar wrongdoing. For street wrongdoing, in contrast, criminal law remains the dominant instrument. Our white-collar crime policy has a much better mix of regulatory strategies, civil remedies, and criminal sanctions than our street crime policy does. Our practice of punishment contributes to unproductive retributivism in street crime law.

Third, the analysis yields practical policy recommendations. Rather than accepting the long-standing argument that corporate crime's tremendous harms require treating it more seriously, we should instead treat street crime more like white-collar crime. We can do this by expanding nascent policies already tested on a local scale but that depart from the punitive trend that now characterizes street crime policy.

My argument proceeds in five parts. The first Part reviews recent literature on norms and other social phenomena, integrating and comparing findings in street and white-collar contexts. These developments prompt the reassessment of criminal law's utilitarian value, an insight acted upon much more in white-collar crime policy than in street crime policy. Part II contrasts our dramatically different approaches to wrongdoing in street and corporate settings, a divergence that looks odd in light of the explanatory power of the social norms literature in both contexts. The next two Parts explore the reasons for, and consequences of, these divergent approaches, arguing that the distinction in enforcement strategies is largely unjustified by differences in offenders, conduct, or harm in the two contexts; the analysis shows why street crime policy remains less effective and less fair than its white-collar counterpart, with higher social costs. Part V suggests how we could move street crime enforcement and punishment productively in the direction of white-collar practice by reducing the role of criminal law in favor of civil and regulatory strategies sensitive to social norm insights.

\section{SOCIAL NORMS, SOcIAL COSTS, AND STRUCTURAL LimitationS}

In this Part, I briefly review some now-familiar social forces that criminal law scholarship has recognized in recent years as central to understanding how law works to regulate behavior. I cover this familiar ground to highlight its insights for white-collar as well as street crime, to provide a reference for the analysis that follows, and to situ- 
ate within it two features somewhat underemphasized in discussions on law and social norms: structural influences and psychological reactions to enforcement strategies such as resentment.

\section{A. Social Norms and Social Influence}

Criminal law scholarship recently has developed several important insights that provide a basis for revising our practice of criminal justice. First is the wealth of attention to the role informal social norms play in governing behavior. Traditional deterrence theory focuses on formal legal sanctions as the important influence on potential offender conduct; if we increase either the certainty of conviction or severity of punishments, rational offenders should reduce their misconduct. This premise presumably underlies the dramatic increase in incarceration rates in the last quarter-century. Social norms describe the informal, nonlegal rules that shape behavior, including decisions to violate the law. Norms arise among all sorts of social groups; they are the informal rules that describe conduct that groups either encourage through rewards or discourage through informal sanctions.

Related to norms is the idea of social influence, which describes the well-known phenomenon that our choices are influenced by what other people choose and approve of. We conform our behavior to that of others in all sorts of ways, from fashion and speech customs to choosing television shows, political candidates, or restaurants; to joining in mob violence, cheating on taxes, or committing other crimes. ${ }^{10}$ The more others around us do something, the more likely we are to approve of it and to do it as well. The more others avoid certain conduct, the more likely we will act similarly. Behavior and preferences are shaped by what those around us are doing, wanting, or approving."

With the recognition of the role that social norms and influence play in fostering law-breaking or law-abiding, scholars have drawn in-

"For information on norms and their relationship to the law, see generally ROBERT C. EllickSON, ORDER WITHOUT LAW 123-240 (1991); Robert D. Cooter, Decentralized Law for a Complex Economy: The Structural Approach to Adjudicating the New Law Mmchant, 144 U. PA. L. REv. 1643, 1656 (1996); Richard H. McAdams, The Origin, Devrlupment, and Regulation of Norms, 96 MiCH. L. REV. 338, 350-51 (1997).

"Set Elliot ARoNSON, THE Soclal ANIMal 13-55 (8th ed. 1999) (giving many' examples of conduct affected by social influence); FRANK A. COWELL, CHEATING THE GOVERNMENT 102-03 (1990) (giving the example of cheating on taxes as a moral behavior influenced by others).

"Dan M. Kahan, Sorial Influence, Social Meaning, and Deterrence, 83 VA. L. REv. 349, $352-61$ (1997) (discussing the interaction between social influence and crime). 
creasing attention to the interaction of law and norms. Legal goals of crime prevention or dispute resolution are more likely to be successful if the law can work in conjunction with social norms. The law can foster compatible social norms-norms that encourage the same conduct that the law wants to encourage-and can diminish the strength of norms that conflict with legal goals, like reduction of harmful wrongdoing. ${ }^{12}$ It can work to shape the social influences that lead people to law-breaking or law-abiding. For instance, if the law can reduce the perception that crime and disorder are widespread in a neighborhood, crime rates are likely to decline; this is a key premise of ordermaintenance or community policing. ${ }^{13}$ It also supports government efforts to ensure that large firms have formal "compliance plans" in place to discourage law-breaking by employees; those plans signal the unacceptability of rule-breaking in a corporate setting. ${ }^{14}$ Moreover, the law may be ineffective if it does not do so. Social norms and influence likely affect crime rates more than the law's deterrent of increased punishment. ${ }^{15}$

The ideas of social norms and influence are related to the notion of local culture, be it within a firm, a street gang, neighboring ranchers, or another social group. ${ }^{16}$ Social norms and influence are strongest among tightly knit social groups. Thus, juvenile gangs are an example of how a group's influence encourages crime, as are certain distressed neighborhoods that perpetuate patterns of crime over time, even as members change. ${ }^{17}$ Another version of this idea comes from Berle and Means's classic thesis of the modern corporation, in which ownership is sufficiently remote that managers can develop a "managerialist culture" not dictated by either owners or the imperatives of

12 I am avoiding terms like "criminal wrongdoing" or "crime commission" at this point because, later in the Article, I emphasize the contingency of whether harmful conduct gets labeled and treated as a crime or a mere civil wrong.

${ }^{13}$ See infra Part V.A.

${ }^{14}$ For a discussion of corporate compliance plans and the effect thereon of federal sentencing guidelines, see Laufer, supra note 8, at 1386-88.

${ }^{15}$ Kahan, supra note 11 , at 359-61.

${ }^{16}$ The seminal work often credited with reviving legal scholars' interest in social norms is EllickSON, supra note 9, which studied norms among ranchers in Shasta County, California.

${ }^{17}$ See Albert J. Reiss, Jr. \& Albert Lewis Rhodes, The Distribution of Juvenile Delinquency in the Social Class Structure, 26 AM. SOC. REv. 720, 728-30 (1961) (giving empirical data correlating delinquency rates with some lower-class neighborhoods); Robert J. Sampson \& William Julius Wilson, Toward a Theory of Race, Crime, and Urban Inequality, in CRIME AND INEQUALITY 37 (John Hagan \& Ruth D. Peterson eds., 1995) (asserting that community-level factors contribute to crime). 
the market. ${ }^{1 \times}$ Organizational theorists have extended this idea by arguing that "[o]rganizational culture forms the 'touchstone' by which individuals behave and act" and is key to explaining how firms can resist or distort even managers' intent. ${ }^{19}$ Reports of "corporate cultures" that foster criminal conduct sometimes explain long patterns of whitecollar crime within firms, ${ }^{20}$ and some regulators try to design enforcement strategies to encourage "corporate virtue" or a social influence toward compliance with the law within a firm. ${ }^{21}$

\section{B. Legitimacy of Law and Enforcement Practices}

Social norms and the localized cultures they help define interact with another factor that impacts how effectively legal regimes work. Public perceptions of the law's legitimacy or moral credibility can either sustain or undermine substantive law. Legitimacy increases both voluntary compliance and cooperation with enforcement. People largely obey the law not because of the fear of punishment, but because they agree with its substantive content and see it as morally credible, a belief that is reinforced by society. They cooperate with enforcement efforts-whether, for example, as jurors who apply the law or citizens who assist police as cooperative witnesses-for similar reasons: they see the rules and their administration as fair and justified."

Both in the white-collar and street settings of criminal law, legitimacy issues affect the structure and efficacy of enforcement policies

"* ADOLPH A. BerLe \& GaRDINER G. MEANS, THE MODERn CORPORATION AND PRIVATE PROPERTY (Harcourt, Brace \& World, Inc. rev. ed. 1968) (1932); FIONA HAINES, CORPORATE REGULATION 23 (1997).

"HAINES, supra note 18, at 25.

Set, e.g., Floyd Norris \& Diana B. Henriques, 3 Admit Guilt in Falsiffing CUC's Books: The "Culture" of Fraud That Shrank Cendant, N.Y. TIMES, June 15, 2000, at C1 ("[T]he largest and longest accounting fraud in history, continuing at least 12 years and costing investors $\$ 19$ billion.... [, occurred because] '[i]t was a culture that had been developing over many years,' . . . 'Tt was just ingrained in all of us . . by our superiors ...." (quoting Cosmo Corigliano, the former CFO of CUC)).

S Sek, e.g., HANES, supra note 18, at 33-36 (discussing social regulation, such as of occupational health and safety).

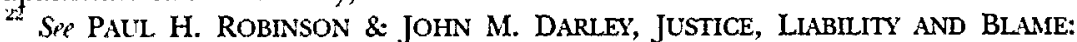
COMMUNITY VIEWS AND THE CRIMINAL LAW 5-7, 201-03 (1995) (analyzing the relationship of community views with the criminal law); TOM R. TYLER, WHY PEOPLE OBEY THE LAW (1990) (finding that the degree to which people view legal authorities as legitimate predicts their willingness to obey the laws); Harold G. Grasmick \& Donald E. Green, Legal Punishment, Social Disapproval, and Internalization as Inhibitors of Illegal Behavior, 71 J. CRIM. L. \& CRIMINOLOGY 325, 332-34 (1980) (arguing that the degree to which people view the law as morally valid predicts their obedience to law). 
and sometimes aggravate the inevitable social costs of criminal enforcement. Yet those issues play out differently in the two settings. On the street crime side, the trend toward punitive incarceration over the last thirty years, which has had disparate effects on the AfricanAmerican community, has clearly undermined the legitimacy of law enforcement in black communities. ${ }^{23}$ Scholars have warned about the substantial legitimacy costs of racially disparate enforcement policies, including the targeting of minority drug offenders more than upperclass white offenders, ${ }^{24}$ the federal sentencing differential between crack and cocaine offenses, and traffic stops motivated by racial profiling. ${ }^{25}$ This legitimacy problem surfaces in "ground level" expressions like nullification of jury votes ${ }^{26}$ and noncooperation with police investigators. $^{27}$ Street crime enforcement policies are less effective and even counterproductive when crucial groups view law enforcement as illegitimate and adopt social norms that undermine the law.

Enforcement in white-collar settings faces comparable legitimacy concerns. Consider the broad scope of the administrative and criminal law that governs wrongdoing and social harm in commercial settings. The deregulation movement over the last two decades is a response to the perceived dysfunction of regulatory regimes governing business. Prominent scholarly accounts of the administrative state describing "how regulation fails" and how those failures prompt a "crisis of legitimacy" exemplify the criticisms. ${ }^{28}$ Health care fraud is a perfect

${ }^{23}$ See Marc Mauer, The Sentencing Project: Young Black Men and the CRIMINAL JUSTICE SYSTEM: A GROWING NATIONAL PROBLEM (1990) (documenting the disproportionate share of African-Americans in prisons). For an example from a generation ago, see REPORT OF THE NATIONAL ADVISORY COMMISSION ON CIVIL. DISORDERS 157 (1968), known as the Kerner Commission report, which found "deep hostility between police and ghetto communities" to be a primary cause of urban riots.

24 See William J. Stuntz, Race, Class and Drugs, 98 CoLUM. L. REv. 1795, 1835 (1998) ("This is no subtle, indirect tilt against black drug crime-here, the bias is both direct and highly visible.").

${ }^{25}$ See RANDALl KENNEDY, RACE, CRIME, AND THE LAW 153, 158, 383 (1997) (discussing race as a factor in law enforcement). See generally DAVDD Col.E, No EQU,LL JUSTICE 169-78 (1999) (describing legitimacy problems caused by racially skewed policies and their adverse effects on crime rates).

${ }^{26}$ Jeffrey Rosen, One Angry Woman, NEW YORKER, Feb. 24/Mar. 3, 1997, at 54 (describing the increase in hung juries in Washington, D.C. criminal trials).

${ }^{27}$ COLE, supra note 25, at 169-78; Jeffrey Fagan \& Tracey L. Meares, Punishment. Deterrence and Social Control: The Paradox of Punishment in Minority Communities (Pub. Law \& Legal Theory Working Paper Group, Columbia Law Sch., Paper No. 10, Mar. 25, 2000) (unpublished manuscript) (examining the effect of criminal punishment on African-American communities), available at http://papers.ssrn.com/ paper.taf?abstract_id $=223148$.

${ }^{28}$ CASS R. SUNSTEIN, AFTER THE RIGHTS REVOLUTION 84-102 (1990) (arguing that 
example. Hospital and physician groups have vocally complained of the Justice Department " using the False Claims Act as a blunt instrument to victimize hospitals who make innocent errors" ${ }^{\$ 29}$ and of regulatory agencies that "have become overly aggressive in their pursuit of cost-containment initiatives in the guise of fraud [prosecutions]." The groups have also complained that the "federal government's tactics have consistently taken a punitive approach with physicians, rather than one of education and prevention" schools, hospitals and teaching physicians into forfeiting millions of dollars of fees billed in good faith." ${ }^{32}$ Another example is the Occupational Safety \& Health Administration ("OSHA"), which is often cited as an example of an ill-conceived, poorly executed regulatory regime. OSHA inspectors long have had a record of constantly citing firms for low-level violations and imposing moderate fines that destroyed any cooperative relationship between firms and regulators. ${ }^{33}$ Yet OSHA's approach has carried no real threat of serious penalties because the agency rarely imposes them. ${ }^{34}$ Similarly, its regulatory scheme has been ineffective in key respects; an OSHA regulation on vinyl chloride, for example, cost the industry $\$ 40$ million to implement, yet was estimated to save only one life annually.

the undemocratic processes and outcomes of regulatory agencies lead to "an outpouring of writing on the crisis of legitimacy").

"Timothy Stoltzfus Jost \& Sharon L. Davies, The Empire Strikes Back: A Critique of thr Backlash Against Fraud and Abuse Enforcement, 51 ALA. L. REV. 239, 243 (1999) (quoting Am. Hosp. Ass'n, Advocacy Papers for the 1998 Annual Meeting: Your Mission on Capitol Hill, at http://www.aha.org/repeal.html (last modified Jan. 20, 1998)).

"RINDOLPH D. SMOAK, JR., AM. MED. ASS'N, BOARD OF TRUSTEES REPORT 34-I98: MEDICIRE "FRAUD AND ABUSE" UPDATE 1 (1998), available at http://www.amaassn.org/meetings/public/int1998/reports/onsite/bot/botrtf/botrep34.rtf.

"Id.

Ass'n of Am. Med. Colleges, Concerns and Recommendations Regarding the Physicians at Traching Hospitals (PATH) Initiative, at http://www.aamc.org/hlthcare/path/ concerns.htm (last modified Dec. 7, 1999).

St JosEPH V. REES, REFORMING THE WORKPLACE: A STUdY OF SELF-REgULATION IN OCCLPATIONAL SAFETY 66-70 (1988) (describing how one company adopted a policy to limit OSHA inspections while also acknowledging agreement with the purpose of the OSHA ACt).

"Sr' LAN AIRES \& JOHN BRAITHWAITE, RESPONSIVE REgulation: TRANSCENDING THE DEREGLLITION DEBATE 8, 49 (1992) ("OSHA has always been a weak regulatory" presence, even if its tiny band of rulebook-oriented inspectors were at times an irritation to American business."); EUGENE BARDACH \& ROBERT A. KAGAN, GOING BY THE BOOK: THE PROBLEM OF REGULATORY UNREASONABLENESS 104-16 (1982) (finding that OSHA's unreasonable rules and surprise checks deter plant managers from complying with regulations); REES, supra note 33 .

"JoHN M. MENDELOFF, The DILEMMA of TOXIC SubSTANCE Regulation 22 (1988); see also W. KIP VICUSI, RISK BY CHOICE 73-104 (1983) (arguing that OSHA's de- 
Finally, environmental regulation is often cited for conspicuous failures and inefficiencies that undermine legitimacy with regulated firms. One of many complaints is that environmental regulators, especially in the 1970 s and 1980 s, employed "command-and-control" strategies that dictated regulatory goals. The requirement that firms use the "best available technology" to remedy nontrivial risks was "exceptionally inefficient" because it "ignore[d] the enormous differences among plants and industries and ... require[d] the same technology in diverse areas-regardless of whether they [we]re polluted or clean, populated or empty, or expensive or cheap to clean up." Sometimes, the requirement was imposed in ignorance of whether the cost of compliance could shut down a plant or industry. ${ }^{37}$

In all of these contexts, punitive enforcement engendered resistance from target groups and their communities, creating a reduced incentive to cooperate with regulators to sustain compliance. ${ }^{38}$ Strategies to minimize resistance, resentment, and diminished credibility are now widely touted as key to optimal law enforcement and prevention. One of the recent prominent arguments against command-andcontrol regulation is that it engenders an adversarial resentment in regulated firms that leads to greater resistance of regulatory standards and less cooperative compliance by firms. Ayres and Braithwaite conclude from empirical studies that a regulatory "strategy based mostly on punishment fosters an organized business subculture of resistance to regulation wherein methods of legal resistance and counterattack are incorporated into industry socialization," other studies as well. ${ }^{40}$ Maintaining the credibility of both the sub-

tailed workplace design standards produced little safety improvement while the agency underregulated significant risks posed by carcinogenic substances).

${ }^{36}$ SUNSTEIN, supra note 28 , at 87

${ }^{37}$ Id. at 87, 92; see also VICUSI, supra note 35, at 98 (describing how the Environmental Protection Agency ("EPA") could have administered the Clean Air Act amendments to "diminish its pathologies ... and to impose lower costs," but "failed to do so").

38 See AYRES \& BRATTHWAITE, supra note 34, at 19-25 (describing how overly punitive, distrusting, and aggressive enforcement engenders resentment and "resistance to regulation" from firms); John Braithwaite, Criminological Theory and Organizational Crime, 6 JUST. Q. 333, 343-45 (1989) (arguing that criminal subcultures are less likely to develop where counterproductive stigmatizing is avoided).

39 AYRES \& BRATTHWAITE, supra note 34, at 20 (citing BARDACH \& KAGAN, supra note 34); see also id. at 49 ("[In p]oorly conceived regulatory strategies ... cooperation [with regulated firms] is destroyed without any of the benefits that can flow from tough enforcement being secured.").

${ }^{+}$See Peter Cleary Yeager, Industrial Water Pollution, in BEYOND THE LAW: CRIME IN CompleX ORGaNizations 97, 138 (Michael Tonry \& Albert J. Reiss, Jr. eds., 1993) (noting pollution field inspectors' "perception[s] that enforcement must be patient 
stance of the law and the means of enforcement is key to increasing law-abidingness and lowering enforcement costs.

\section{Social Capital and Social Costs}

The social capital, or social organization, of communities also affects compliance. Scholars have described how the law can contribute to, or decrease, social capital. Fagan and Meares argue in a recent paper that criminal justice policies undermine social infrastructure; the policies reduce employment opportunities, family income and stability, and adult supervision of children, thereby aggravating crime problems by reducing informal controls and support for lawabidingness. ${ }^{~}$ Excessively punitive law enforcement may be aggravating "criminogenic" influences, increasing crime through ill-guided strategies designed to reduce it. Moreover, when ancillary costs are excessive, they help undermine the legitimacy of criminal law and enforcement policy, which can in turn make enforcement and prevention efforts less effective.

Comparable concerns animate debates over regulation of wrongdoing in corporate settings. The generation of adversarial cultures of resistance to regulation describes one way that the social capital necessary to minimize wrongdoing is decreased. Efforts to reinvent regulation in a more cooperative and collaborative form by supplanting command-and-control regulation aim to increase the social infrastructure-the attitudes within firms and industries and the relations between firms and enforcement officials-thereby decreasing wrongdoing without resorting to the deterrence of punitive sanctions. ${ }^{42}$ While criminal law scholars and policymakers in recent years have given some attention to such cooperative strategies, ${ }^{43}$ regulatory scholarship

and 'reasonable' lest it produce uncooperative attitudes toward compliance on the part of the regulated businesses").

"Fagan \& Meares, supra note 27, at Part IV.

" Cooperative regulatory strategies that foster partnerships between public and private players and replace punitive enforcement are a common theme in regulation

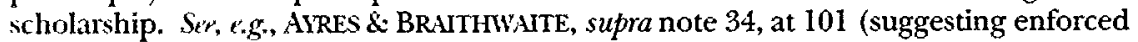
self-regulation); REES, supra note 33, at 10 (studying OSHA's Cooperative Compliance Program); Daniel A. Farber, Taking Slippage Seriously: Noncompliance and Creative Comfluchte in Emiranmental Law, 23 HARV. ENVTL. L. REV. 297, 305-11 (1999) (recognizing that regulators and courts give private parties room for noncompliance); Jody Freeman, Collaborativ' Governance in the Administrative State, 45 UCLA L. REV. 1, 21-33 (1997) (using EPA and OSHA programs as examples); Sidney A. Shapiro \& Randy Rabinowitz, Voluntary Regulatory Compliance in Theory and Practice: The Case of OSHA (Nov. 11, 1999) (unpublished manuscript, on file with author).

"Sre, tg, Fagan \& Meares, supra note 27, at Part III (discussing social capital and 
and agency practice have a much longer and more extensive record of attention to this issue. Such strategies have animated major policy revisions in the past two decades."

Attention to social capital raises awareness of the social costs not only of wrongdoing, but also of sanctions and enforcement strategies that respond to wrongdoing. Criminal sanctions impose costs on others beyond the defendant, and they impose costs on defendants beyond the formal components of punishment. Taking full account of these social costs is crucial to assessing whether a criminal or civil enforcement regime functions well. Within the street crime category, the dominant example of such costs is the disproportionate burden placed on the black community. Criminal sanctions hurt offenders and those connected to them by social networks in significant ways. Criminal records and prison time, in addition to engendering anger and resentment in offenders, ${ }^{45}$ significantly reduce employment prospects and earning power in the later years and also correlate with increased crime activity after prison. ${ }^{46}$ Those reduced prospects make investment in job skills seem less promising, leading convicts to invest less in job-readiness education. ${ }^{47}$ Those injured by an ex-convict's limited employment prospects include family members and potential family members, as ex-convicts are less appealing marriage prospects, leading to more households headed by single women. Removal of young adults from the community to prison means fewer adults are available to supervise children. Prison can aggravate antisocial attitudes and resentments can lead to further wrongdoing. ${ }^{48}$ The combined negative effects of street crime laws and enforcement choices tear at the fabric of disadvantaged communities, aggravating the social

structural influences on crime in poor, African-American neighborhoods).

* Two examples are OSHA's Cooperative Compliance Program, REES, supra note 33, at 10, and the EPA's strategy of substituting agreements on Supplemental Environmental Projects for some monetary sanctions, David A. Dana, The Uncertain Merits of Environmental Enforcement Reform: The Case of Supplemental Environmental Projects, 1998 WISC. L. REV. 1181, 1187.

45 DANIEl VAN NESS \& Karen H. Strong, Restoring Justice 43 (1997); Martin WRIGHT, JUSTICE FOR VICTIMS AND OFFENDERS: A RESTORATIVE RESPONSE TO CRIME 11, 40 (2d ed. 1996).

46agan \& Meares, supra note 27.

47 See id. ("A released convict may perceive further investment in human capital to be useless because he may understandably reason that sinking money and time into education and training will not overcome the stigma of a felony conviction on a job application.").

${ }^{48}$ See, e.g., Michael Berryhill, Prisoner's Dilemma: Did the Texas Prison System Kill James Byrd?, NEW REPUBLIC, Dec. 27, 1999, at 18 (arguing that incarceration aggravated inmates' racist views and led to the brutal killing of James Byrd). 
problems in those communities of low employment rates, family instability, and the lack of social organization that facilitates lawabidingness. These costs are imposed especially on low-income minority communities, which have the least capable social infrastructures to compensate for them. African-Americans are incarcerated at rates drastically higher than their percentage of the population. ${ }^{49}$ Moreover, this disproportionate focus of criminal justice on racial minorities infuses interpersonal relations and public consciousness with racialized images of crime and criminals." All of these are ancillary costs to a social policy confronting street crime that emphasizes criminal conviction and imprisonment.

Administrative law literature is full of accounts of regulatory efforts that have proven ill-conceived and counterproductive in comparable ways-for example, by failing to meet the social purposes the statutes or regulations aimed to address, creating perverse side effects, imposing costs that exceed benefits, ${ }^{51}$ and, through such missteps, engendering "business subculture[s] of resistance" to enforcement goals." Scholars repeatedly find that "administrators take insufficient account of the systemic effects of regulatory controls" ${ }^{, 33}$ and act in selfinterested or myopic ways that result in not only "irrational and overzealous regulation ... [but also] inadequate protection." ${ }^{\text {5it }}$ Regulatory dysfunction stems from "a failure of diagnosis or of coordination" causing firms to incur compliance costs not outweighed by the regulation's benefits, thus aggravating one social harm as it mitigates

"S $S_{r^{\prime}}$ CoLE, supra note 25, at 144 ("From 1986 to 1991, the number of white drug offender incarcerated in state prisons increased by 110 percent, but the number of black drug offenders increased by 465 percent."); MLAUER, supra note 23, at 145 (documenting the disproportionate number of African-Americans in prisons and noting a similar disparity for juvenile drug arrests); DOUGLAS C. MCDONALD \& KENNETH E. Cirison, SENTENCING in the Federal Courts: Doks RaCe Matter? THE TRLNITION TO SENTENCING GUIDELINES, 1986-90, at 1-2, 13-17 (1993) (documenting longer sentences for black offenders than for white offenders and attributing the difference in part to harsher sentences for crack than for cocaine, but also finding differences for larceny and weapons offenses not explained by nonracial factors).

"Sw JODY DAVD ARMOUR, NEGROPHOBLA AND REASONABLE RACISM: THE HIDDEN COSTS OF BEING BLACK IN AMERICA 81-101 (1997) (discussing how "negrophobia" arises in private and public narratives); KATHERIN $\mathrm{K}$. RUSSELL, THE COLOR OF CRIME: Raclal Holxies, White fEar, Black ProtectionisM, Police Harassient, and OTHER MLACROAGGRESSIONS 1-13 (1998) (describing perceptions of black people).

SUNSTEIN, supra note 28 , at 74 .

AIRES \& BRATHWAITE, supra note 34, at 20.

"SUNSTEIN, supra note 28 , at 98 .

Id. at 99 .

In. at 105. 
another. The OSHA regulation of vinyl chloride noted above is one example $;^{56}$ regulation of the ethanol industry as a strategy for reducing air pollution may be another. ${ }^{57}$

Another form of social costs can accompany corporate criminal punishment. Scholars have noted that firms typically suffer a measurable decline in stock value as a result of criminal sanctions, arguably resulting in inefficient over-deterrence. ${ }^{58}$ Sanctions against firms may hurt workers, their families, and their local economies. Such harm to third parties can affect charging discretion-for example, prosecutors may forgo criminal punishment for civil remedies against fraudulent health care providers if the offender is the sole provider for a community, thereby aiming to reduce the social harm of lost health care services. ${ }^{59}$ In both street and white-collar settings, then, punishment can have significant social costs for which officials often do not fully account, making some enforcement strategies counterproductive. One finds descriptions of enforcement approaches in both administrative and criminal contexts described as "paradoxes" because they undermine their very goals and purposes. ${ }^{60}$ Yet responses to critical appraisals of social costs and diminished social capital differ substantially in street and white-collar contexts in how they inform enforcement choices.

${ }^{56}$ See supra note 35 and accompanying text.

${ }^{57}$ See William M. Brown, The Renewable Oxygenate Requirement: A Boon for the Environment or a Boondoggle for the Ethanol Industry?, 41 N.Y.L. SCH. L. REv. 1299 (1997) (discussing the EPA's efforts to reduce air pollution and the effect on the ethanol industry, and noting the possibility that the EPA's regulations could lead to increased air pollution).

See Cindy R. Alexander, On the Nature of the Reputational Penalty for Corporate Crime: Evidence, 42 J.L. \& ECON. 489 (1999) (describing extralegal sanctions for corporate crime).

${ }^{59}$ See U.S. DEP'T OF JUSTICE, FALSE CLAIMS ACT GUIDANCE, reprinted in 2 Health Care Fraud Rep. (BNA) 459, 460-61 (1998) [hereinafter FCA GUIDANCE] (stating that Justice Department attorneys should consider alternative remedies and the potential impact of enforcement decisions on communities before initiating fraud actions against health care providers); Jost \& Davies, supra note 29, at 285 (arguing that in such cases the community would suffer "special harm by the provider's exclusion").

${ }^{60}$ See HAINES, supra note 18, at 220 (describing "a paradox where demand for increased accountability through the courts could produce less virtue," or compliance, in some firms). Compare SUNSTEIN, supra note 28, at 106 (discussing the "simple empirical truths" and four major administrative examples of "paradoxes of the regulatory state"), with Fagan \& Meares, supra note 27 (analyzing the paradoxical effects of criminal punishment). 


\section{Structural Influences}

Another consideration that helps to explain misconduct has received somewhat less attention in legal scholarship on social norms. Structural conditions, particularly an actor's economic setting, greatly affect that actor's tendencies toward wrongdoing. Contemporary theorists have moved beyond the economic determinism of Marxist analyses on this point but still draw attention to the structural demands that constrain actors, whether they be individuals within community subgroups or firms in a given market sector. ${ }^{61}$ Structural restraints and local cultures-a community's "street" culture or a firm's corporate culture, for example-interrelate. Culture is not dictated by structural limits or economic pressures; not all groups in distressed communities turn to drug crime as a substitute for legitimate economic activity. Equally, not all firms in competitive markets regularly subvert costly regulatory restraints, which we might think of as a rough equivalent to bans on drug trafficking in locales with few other opportunities. Nonetheless, economic position is a form of structural pressure that makes some cultures, and individual choices, more or less likely. William Julius Wilson's work describing the social and cultural consequences of structural pressure, including higher crime rates in communities deprived of job opportunities and, thus, traditions of regular employment, broadly fits this idea. ${ }^{62}$ Comparably, there is considerable empirical evidence that smaller firms with thin capital and profit margins more frequently engage in wrongdoing ranging from fraud to lower safety standards and breach of environmental rules." Larger, wealthier firms arguably do not as often face the same

1. HANES, supra note 18, at 20-23 (discussing Marxist analysis and small firms); Yeager, supra note 40 , at 126-27, 130-31 (discussing how the financial health of large and small firms correlates with environmental violations and success in defending against the EPA).

"12 See generally WILliam Julius WILSON, WHEN WORK DisapPEars: THE WORLD OF THE NEW URBAN POOR (1996) (describing the cultural side effects of high crime rates in the inner-city ghetto); Sampson \& Wilson, supra note 17 (inquiring into the community structures of race and crime).

See, e.g., Hugh D. Barlow, From Fiddle Factors to Networks of Collusion: Charting the Waters of Small Business Crime, 20 CRME L. \& SOC. CHANGE 319 (1993) (noting the costs of small business crime and calling for criminologists to redirect their efforts toward such crimes); William N. Leonard \& Marvin Glenn Weber, Automakers and Dealers: A Study of Criminogenic Market Forces, in WHITE-COLLAR CRIME: OFFENCES IN BUSINESS, Politics, AND THE PROFEssions 133 (Gilbert Geis \& Robert F. Meier eds., 1977) (discussing white-collar offenses among car dealers); Adam Sutton \& Ronald Wild, Small Business: White-Collar Villains or Victims?, in UNDERSTANDING CRIME AND CRIMINAI JusTICE 78, 79 (Mark Findlay \& Russell Hogg eds., 1988) ("[W] hen prosecutions are compared with estimates on actual numbers and types of enterprises operating in the 
pressures for survival, in part because they may have "regulatory economies of scale" that more easily manage or spread compliance costs. $^{64}$ Attention to those sorts of pressures provides an explanation for misconduct that is an alternative to theories that merely emphasize an actor's lack of virtue, moral character, or independent local culture. And that sort of alternative understanding, recognizing structural pressures, has implications for prevention, enforcement, and punishment policies. Legal policies that can take account of these factors are more likely to succeed at the goals of crime prevention and harm reduction.

This collection of ideas about extralegal influences on wrongdoing has important implications for enforcement and the design of legal sanctions, but it also affects deeper conceptual premises of criminal law. Criminal law imposes responsibility based on strong ideas of free will. Criminal law by its very design and operation narrows the focus of concern, and thus the basis for legal responsibility, to a limited time frame and set of influences and situational factors around the offender's acts. Criminal law resists structural and contextual explanations for offender conduct; opening the door to recognizing those influences is a slippery slope to exculpation based on notions of determinism, something like a "rotten social background" defense, or excuses based on peer pressure or employer/coworker pressure falling far short of duress. Even while scholars, and to some extent policymakers, increasingly acknowledge the reality of social influences on individual and group conduct, criminal law must repress those realizations and continue to operate on a "notoriously shaky" idea of free will. $^{63}$ As a result, while recognition of social influence makes its way into some realms of criminal justice policy, particularly in prevention

Australian economy, they seem to suggest that the larger a company becomes, the more likely it is to be law-abiding."); Steve Tombs, "The Causes of Coal-Mine Accidmis", Wonker Autonomy, and the Myth of the Small Firm, 19 INDUS. REL. J. 248 (1988) (responding to the argument that worker autonomy in small business leads to higher accident rates); Yeager, supra note 40, at 126-27, 130-31 (noting that larger firms succeeded more against EPA enforcement while "poorer financial health led to greater involvement in environmental violations, particularly among companies operating in industries with capital liquidity and turnover problems"); see also William S. Laufer, A Study of Small Business Compliance Practices, in PROCEedings of THE SECOND SYMPOSIUM ON CRIME AND PUNISHMent IN THE UNITED STATES, CORPORATE CRIME IN AMerici: STRENGTHENING THE "GOOD CITIZEN" CORPORATION 135 (1995) (noting that small businesses account for at least ninety percent of corporate convictions in the federal courts annually).

${ }_{64}^{64}$ Yeager, supra note 40 , at 130.

65 Meir Dan-Cohen, Responsibility and the Boundaries of the Self, 105 HARV. L. REV. 959,960 (1992). 
and enforcement strategies, substantive doctrine is largely resistant to it. Nonetheless, the power of the ideas has made its way into isolated pockets of rules and policy. ${ }^{16}$

Furthermore, these ideas of social influence, capital, costs, and structure affect the continuing debate between the long-dueling rationales for criminal law, deterrence theory, and retributive or desertoriented theory. Social influence ideas ultimately support utilitarian rationales, although they call for substantial revision of strategies that rest solely on the deterrent effect of formal sanctions on isolated rational actors. On the other hand, because they challenge the premise of an autonomous, free-willed actor unhindered by relevant contextual factors, they subtly challenge retributive theory. One whose social influences and daily moral education lead him away from the dictates of formal rules can be seen as less blameworthy for violating those rules. That challenge is far from sufficient to move us to accept fullfledged excuses based on social influence, yet it helps to shift thinking away from criminal punishment of individuals as a dominant goal of the law and toward a mix of strategies in which we will trade off criminal liability for more effective means of prevention, restitution, and even punishment. Social influence theory shifts thinking from retribution to new forms of deterrence, from punishment to prevention, and ultimately from criminal law to civil. In this way it facilitates the contingency of criminal law. It affects our choice to use criminal law when we have, or can develop, civil and regulatory alternatives. Importantly, though, these challenges posed by recognition of social influences play out very differently in the realms of street and corporate criminal law. The next Part explores two respects in which the conceptual underpinnings of criminal law evolve in different ways in the street and corporate sectors, due in large part to varying acceptance of social influence arguments.

\section{DINERGENT STRATEGIES FOR WRONGDOING IN STREET AND WHITE-COLLAR SETTINGS}

Enforcement officials in both street and corporate crime sectors can choose from a range of policy strategies to confront wrongdoing.

\footnotetext{
"St' Laufer, supra note 8 (discussing the "good corporate citizen" movement); Memorandum from Eric H. Holder, Jr., U.S. Deputy Attorney General, to Heads of Department Components, All United States Attorneys (June 16, 1999), http://www.bna.com/prodhome/leg/guidance.html [hereinafter Holder] (listing as one factor to be considered in whether to charge a corporation the "existence and adequacy of the corporation's compliance program").
} 
Scholarship and enforcement policy in recent years have explored which strategies work most effectively given insights about social influence, legitimacy problems, structural limits, and the social costs of different enforcement options. Both street and corporate crime sectors have a history of taking relatively little account of these factors and relying on command-and-control, punitive-oriented approaches to deter wrongdoing. Fairly recently, however, strategies in these two sectors have significantly diverged ${ }^{67}$ so that regulators of corporate wrongdoing increasingly choose more cooperative, compliance-seeking strategies aimed at encouraging law-abidingness, even as white-collar criminal sanctions have increased. The scholarly criticisms of regulatory dysfunction combine with politically salient complaints from regulated firms to undermine the legitimacy of command-style regulation and motivate a gradual but fairly widespread reform. Policies targeting street-level wrongdoing, meanwhile, remain dominated by punitive command-and-control strategies-the traditional mode of criminal law-that are increasingly rejected in corporate regulation.

Deregulation and reinvention of regulation have been central fixtures of regulatory policy debates for two decades and recently have had moderate success in legislation, enforcement policies, and the scholarly literature. ${ }^{68}$ These debates address the inevitable choice for enforcement policy between command-style punitive approaches and cooperative, compliance-seeking strategies aimed at encouraging lawabidingness. ${ }^{69}$ I will use Ayres and Braithwaite as providing a leading example of scholarship criticizing punitive regulation and reconceiving regulation on a model of collaboration and dialogue between regulated firms and government officials. They describe regulators'

i7 I do not mean to overstate the recency of this divergence. There have always been great distinctions in how we address white-collar and street-level wrongdoing; we have long used civil and regulatory mechanisms for the former that have no parallels for the latter. I refer here more to the shift away from command-and-control, which is still the approach that characterizes street crime enforcement, within regulatory policy and theory over the last two decades.

${ }^{68}$ See AYRES \& BRAITHWAITE, supra note 34, at 7-12 (reviewing the regulatory philosophies of the Carter and Reagan administrations); HANNES, supra note 18, at 8 ("Instead of renewed determination to prosecute, the key concept in this latest shift in the regulatory debate is a perceived need to encourage trust between regulator and regulated."); SUNSTEIN, supra note 28, at 30-31, 99-100 (detailing the deregulation of the $1970 \mathrm{~s}$ and $1980 \mathrm{~s}$ and suggesting that regulatory efforts are "hampered by the power of well-organized private groups"); Rena I. Steinzor, Reinventing Environmental Regulation: The Dangerous Joumey from Command to Self-Control, 22 HARV. ENVTL. L. REV. 103 (1998) (critically assessing regulatory reinvention in environmental law).

${ }^{69}$ See AYRES \& BRAITHWAITE, supra note 34, at 20 (comparing "deterrence" versus "compliance" models of regulation). 
options between these two broad approaches as choices between a focus on punishment or persuasion. In a series of works on business regulation, Ayres and Braithwaite have argued for an "enforcement pyramid" strategy, in which regulators mostly rely on cooperation and self-regulation - the base of the pyramid-but have increasingly punitive options up to command regulation with nondiscretionary punishment at the top of the pyramid as a background threat-the "benign big gun"-for use on the occasional noncompliant firm. ${ }^{\text {" }}$ Such a strategy fosters firm cooperation with law enforcement goals-even costly ones-and relies on regulated firms' respect for the legitimacy of the enforcement regime. This accords with Tom Tyler's wellknown work on procedural fairness, which has found that people accept the legitimacy of justice systems and even unfavorable outcomes much more when they experience the system as procedurally fair." "[R] egulators should not do without an image of invincibility in the background, and should be reluctant to push punishment to the foreground of day-to-day regulatory encounters. They do best when they are benign big guns." ${ }^{\text {T2 }}$

Corporate regulation has always worked within a more utilitarian tradition than the expressive, desert-oriented one that typifies contemporary street crime policy. ${ }^{73}$ Partially as a result, cooperationoriented regulatory strategy has found much wider acceptance in white-collar contexts than in street-level contexts. ${ }^{74}$ For example, the Ayres-Braithwaite strategy focuses on prevention and compliance, whereas street crime policies focus on wrongdoing detection and severe, expressive punishment.

The rationales behind the Ayres-Braithwaite proposal are now widely accepted in regulatory debate and increasingly characterize enforcement practice. A driving motivation of this approach is to reduce the "psychology of resentment," the prospect that firms and individuals confronted with inflexible commands and harsh punishments adopt a critical, noncooperative posture toward compliance goals and enforcement personnel. ${ }^{73}$ Those attitudes foster norms and legitimacy

"Id. at 39 .

TI TYLR, supra note 22 , at 25.

II $I$. at $48-49$.

7. Ste infra Part IV.A (discussing the strength of retributive and deterrence rationales).

Set AlREs \& BRAITHWAITE, supra note 34, at 19-20 (exploring regulatory assumptions about corporate actors).

Ser id. at 27 (suggesting that regulatory "forgiveness is advocated more for its importance in building a commitment to comply in [the] future"); HAINES, supra note 
problems that work against legal compliance. Conversely, new regulatory strategies aim to foster self-regulation, voluntary compliance, and a sense of social responsibility. Cooperative, nonconfrontational approaches begin enforcement with dialogue and efforts to coax voluntary responses, followed only later, for a recalcitrant subgroup, with warnings, civil sanctions, and criminal prosecution. They strengthen the legitimacy of the legal rules and social influences that support them. Regulators and scholars have become increasingly sensitive to the importance of such informal, nonlegal means of fostering compliance; the goal is to design enforcement strategies that foster social norms, corporate cultures, and market contexts in which "corporate virtue" can develop and be maintained. ${ }^{76}$

Street crime policy has not followed anything similar to the reformist turn we see in the regulation of white-collar wrongdoing. States now employ the death penalty at a rate not seen in two generations. ${ }^{77}$ Prison populations and incarceration rates have steadily increased for two decades. ${ }^{78}$

Mandatory minimum sentences, including harsh recidivist laws, now govern punishment for many street crimes. ${ }^{79}$ The number of people in jails and prisons exceeded two million for the first time in

18, at 220 (explaining how regulation can engender "[d] efiant organizations"); Lawrence W. Sherman, Defiance, Deterrence, and Irrelevance: A Theory of the Criminal Sanction, 30 J. RES. CRIME \& DELINQ. 445, 452 (1993) ("People obey the law more when they believe it is administered fairly then when they don't."); Yeager, supra note 40 , at 138 (linking the attitude of regulatees to the type of violation found).

${ }^{76}$ See Holder, supra note 66 (providing guidance on Justice Department criteria for charging corporations with crimes and acknowledging that "management is responsible for a corporate culture in which criminal conduct is either discouraged or tacitly encouraged" and "a history of [criminal] conduct may be probative of a corporate culture that encouraged, or at least condoned, such conduct"); see also HAINES, supra note 18 , at 36-40 (discussing policies to encourage firm cultures of "corporate virtue" and arguing that they vary in likelihood of success).

${ }_{77}$ See, e.g., Bureau of Justice Statistics, U.S. Dep't of Justice, Key Crime $\mathcal{F}^{\circ}$ Justice Facts at a Glance, http://www.ojp.usdoj.gov/bjs/glance.htm (last modified Feb. 1, 2001) [hereinafter Key Crime $\mathcal{F}^{2}$ Justice Facts] (showing that more inmates were executed in 1999 than in any year since the early 1950s).

${ }^{78}$ Id.

${ }^{79}$ See, e.g., Anti-Drug Abuse Act of 1986, Pub. L. No. 99-570, 100 Stat. 3207 (stating a mandatory minimum sentence of ten years for possessing fifty grams of crack cocaine with intent to distribute and a mandatory minimum sentence of ten years for possessing five thousand grams of powder cocaine with intent to distribute); CAL. PENAL CODE $\$ 667(\mathrm{e})(2)(A)$ (West 2000) (describing California's three-strikes law); BUREAU OF JUSTICE STATISTICS, U.S. DEP'T OF JUSTICE, THE SOURCEBOOK OF CRIMINAL JUSTICE STATISTICS, $1998 \$ 5$ (reporting sentencing data for federal and state courts); 16B AM. JUR. 2D Constitutional Law $\$ 656$ (1998) (surveying three-strikes laws and similar recidivist statutes). 
1999, average sentence lengths have increased, and offenders are more likely to have parole revoked for minor violations. ${ }^{80}$ In the last decade, many states have lowered the age by which juvenile offenders face adult criminal courts and prisons. ${ }^{81}$ Furthermore, punitive prosecutorial policies, such as the prosecution of pregnant mothers who expose their fetuses to drugs, demonstrate a commitment to harsh criminal approaches."

Why this distinction in strategies? Common assumptions are that these are very different types of conduct, harm, and offenders and thus they require very different enforcement and punishment strategies. Painting with an overbroad brush, street offenders are outside the mainstream norms of society. More committed to subcultures or simply irrational, violent, or greedy, their crimes are clearly intentional. White-collar offenders, on the other hand, except for those white-collar crimes that plainly mimic street crimes-for example, embezzling from an employer is stealing and credit card or insurance fraud are just other forms of theft-are more reasonable, mainstream people. Their crimes often are unintentional or technical in nature, thereby allowing white-collar offenders to be dealt with differently than street criminals. We can negotiate with them, gain their cooperation in investigations and self-enforcement plans, deter them with civil fines, and thereby deal with them more in a regulatory mode than a criminal one.

In fact, however, many important forms of white-collar wrongdoing are clearly intentional and are covered by criminal statutes with strong mens rea requirements. ${ }^{83}$ There are some structural distinctions that shape divergent enforcement policies, such as offenders' wealth and the legal identity of firms compared to the nonidentity of street offenders' contexts, both of which I address below. As the survey of social phenomena discussed in Part I suggests, however, the two

Fox Butterfield, Number in Prison Grows Despile Crime Reduction: Stricter Parole and Sintrincing Laus Cited, N.Y. TIMES, Aug. 10, 2000, at Al0.

The Sentencing Project, Prosecuting Juveniles in Adult Court: An Assessmint of Tronds and Consequences (Briefing/Fact Sheet No. 1090), http:// whw.sentencingproject.org/brief/juveniles.html (last visited Mar. 19, 2001) ("Since 1992, almost every state has made it easier to try juveniles as adults.").

For a critical description of this strategy employed in two dozen states in the last decade, see Dorothy E. Roberts, Unshackling Black Motherhood, 95 MICH. L. REV. 938 (1997).

Sir Sharon L. Davies, The Jurisprudence of Willfulness: An Evolving Theory of Excusthle Igurance, 48 DukE L.J. 341, 342-48 (1998) (describing the judicial trend of interpreting federal criminal statutes with "willfulness" mens rea elements, which include many white-collar offenses, as requiring defendant's knowledge of the law). 
sectors of wrongdoing are more alike than different in the nonlegal considerations that should drive enforcement; the differences do not come close to accounting for the sharply divergent enforcement approaches. Most of the salient distinctions that should prompt strategy shifts cut across the white-collar/street sectors. Small, economically marginal firms facing structural pressures toward crime, for instance, are comparable to subgroups of street offenders for whom cooperative, compliance-fostering prevention strategies may be less appropriate, ${ }^{84}$ but, as argued in Part V, other less punitive strategies may work well. Wrongdoing in both white-collar and street sectors, however, is generally responsive to the approaches that increasingly characterize corporate regulation. The alternative to punitive enforcement imposes high social costs in both realms.

Divergent enforcement strategies have more to do with the conceptual choices we make in describing and interpreting wrongdoing. Those choices have huge consequences for the politics and efficacy of criminal enforcement policy. Furthermore, they shape our basic conceptions of culpability. I make that case in the following two Parts of this Article. The next Part unpacks one doctrine-corporate liability-that exemplifies these conceptual distinctions between whitecollar and street offending and their consequences. The subsequent Part offers a broader analysis of conceptual and political forces that drive white-collar and street policies in unproductively divergent directions.

\section{CONCEPTUAL AND POLITICAL IMPLICATIONS OF CORPORATE LIABILITY}

The distinctive strategies we use to address comparable wrongdoing, occurring under comparable social dynamics, have significant implications for the efficacy of enforcement, the expressive and moral blaming functions of criminal law, and even the political and social structure of which punishment is a part. The dominant distinction between the street and white-collar crime enforcement approaches is the availability of civil and nonpunitive options in the latter. But to begin this inquiry, look first at a distinction within criminal law-corporate criminal liability. That doctrine initially appears to increase

${ }^{84}$ See Laufer, supra note 8, at 1388 (discussing compliance rates of small firms and noting that they account for the vast majority of corporate criminal convictions each year); supra text accompanying notes 54-56 (finding that unsuccessful implementation strategies cause regulatory failures). 
criminal punishment for white-collar offenders, and indeed it can. Its conceptual premises, however, conflict with traditional criminal law premises in an important way that strengthens a false distinction about social influence on criminal actors and, indirectly, helps to support civil approaches to white-collar wrongdoing.

The doctrine permitting corporate criminal liability is broad, particularly in federal courts, where most corporate prosecution occurs. Corporations can be held liable on a respondeat superior theory for acts of any agents-not merely high-ranking officers-who are acting within the scope of their employment and for the benefit of the corporation. Those two qualifications have been interpreted narrowly. The agent can be motivated partly by other motives, such as personal gain, and the corporation need not have authorized or overtly encouraged the agent's criminal action. Similarly, the corporation need not actually benefit, as long as its benefit was part of the agent's intention.

Why such breadth for corporate liability? One answer may be utilitarian in nature. Corporate liability will deter agents' wrongdoing within the firm, and by putting corporate assets at risk, we give owners and managers more incentive to monitor agent conduct. That is a common judicial rationale, and one offered by the Justice Department in its Guidelines for Prosecution of Corporations. ${ }^{86}$ That rationale is weak, however. First, the feasibility of increasing shareholder or officer monitoring through criminal liability is questionable. Second, that goal can be fully met with civil liability alone. ${ }^{87}$ Some scholars argue that corporate liability may even be counterproductive, increasing crime by discouraging firms themselves from detecting their agents'

'Si Pe PaMela H. BUCT, White Collar CRIME: CASES AND Materials 992-1005 (2d ed. 1998) (discussing the criminal liability of corporations and corporate executives); Kathleen F. Brickey, Corporate Criminal Liability: A Primer for Corporate Counsel, 40 Bus. L.1w: 129, 131 \& n.11 (1984) (charting the development of the doctrine through case law); Pamela H. Bucy, Corporate Ethos: A Standard for Imposing Corporate Criminal Liability. 75 MINN. L. REV. 1095, $1102-05$ (1991) (comparing the two current standards of corporate criminal liability: the respondeat superior approach and the Model Penal Code approach); Holder, supra note 66 ("Under the doctrine of respondeat superior, a corporation may be held criminally liable for the acts of its directors, officers, employees, and agents.").

Ser Holder, supra note 66.

${ }^{37}$ Ser Daniel R. Fischel \& Alan O. Sykes, Comporate Crime, 25 J. LEGal STUD. 319,321 (1996) ("At best, the case for corporate criminal liability must rest on the need to correct some deficiency in the system of civil liability. But a close look at the cases reveals no such deficiency most of the time."); Mann, supra note 3 , at 1797-98 (noting the proliferation of civil punitive damages as a means to punish and deter). 
wrongdoing and thereby increasing their own liability. ${ }^{* 8}$

Moreover, a corporation is merely people joined in voluntary, cooperative ventures. Behaviorally, though not legally, a firm is much like many other coordinated, group endeavors in which some people influence others. There is no obvious reason why we need tools in the corporate setting to address some individuals' influence on others beyond what criminal law already provides. Criminal law has well established ways to address conduct that wrongly compels others to commit crimes-for example, liability for coercion and duress defenses-or wrongly encourages or aids others in crime commission-for example, complicity and accomplice liability. And when another's influence on an actor's conduct falls short of complicity-such as taunting, badgering, or threatening disassociation from group membershipno liability follows, even though it may be a real influence. Even more firmly established is the rule that courts will not assess liability for failing to discourage or prevent others from committing crimes, or for not reducing their opportunities to do so. ${ }^{89}$ Yet the utilitarian function of corporate liability does just that.

In that sense, corporate liability is a somewhat odd weapon within the traditional criminal doctrine. It assumes that those actors surrounding the agent-perpetrator, making up the relevant social context in which she commits crime, are a critical influence on the agent and yet are not aiders-abettors. These actors not only influence the agent to a degree that could change his conduct and prevent his crime; their influence, or responsibility to exercise it, is so significant that it deserves to be governed by criminal liability. Some of that influence may be of the sort covered by the complicity doctrine, but it does not have to be in order to incur liability for the firm. It is liability for being a social influence at a level below complicity.

The doctrine thus gives stronger attention to the organizational or social context of criminal conduct than elsewhere in criminal law. Holding a corporation rather than individuals liable for crimes suggests that the target for both retributive blame and utilitarian deter-

${ }^{8}$ See, e.g., Jennifer Arlen, The Potentially Perverse Effects of Corporate Criminal Liability, 23 J. LEGAL STUD. 833, 836 (1994) (pointing to the introduction of corporate enforcement costs as a source of increased corporate crime).

${ }^{89}$ See JOSHUA DRESSLER, UNDERSTANDING CRIMINAL LAW $\$ 9.06[\mathrm{~A}]$, at 86 (2d ed. 1995) ("Subject to a few limited exceptions, a person has no criminal law duty to rescue or render aid to another person in peril, even if the person imperiled may lose her life in the absence of assistance."); A.D. Woozley, A Duty To Rescue: Some Thoughts on Criminal Liability, 69 VA. L. REv. 1273 (1983) (arguing in favor of making failure to give aid to persons in physical danger an offense). 
rence is not, or at least not solely, the individual, but the social context that influenced him to carry out criminal activity. The doctrine recognizes that social settings can be "criminogenic." They tend to foster or produce criminal behavior and can also reduce it. Those responsible for that context share the blame. With corporate liability, the assignment of culpability is muddied in a way that it is not in street crime. While not excusing the individual actor, corporate liability blames those who influenced him as well. ${ }^{1 \%}$ It acknowledges that responsibility, in some settings at least, is not fully captured by the model of individual moral agency that underlies traditional criminal law.

This is not an argument against corporate liability. Rather, the point is that the doctrine of corporate liability is a unique acknowledgment of the relevance of social norms and influence on individuals' criminal conduct. It implies that, to prevent crime, we need to direct liability not only at the individual actor, but at the social context in which she acts-the social context that shares responsibility for her criminal conduct. Once a crime is committed, the expression of social disapproval is justly directed at those contributing to the social context as well as the individual. And if social context is a target for deterrence efforts as well as blame, then a better understanding of how contexts work might prompt us to find effective nonpunitive prevention strategies that work better. That opens the door for newer regulatory strategies.

Described that way, it is easy to see how corporate liability contrasts with concepts underlying the law of traditional street crime. Our most troubled and stressed communities, particularly in inner cities, are surely as criminogenic as the worst firms that incur corporate liability. "Yet, we do not give the same weight to social influence on street offenders as corporate criminal offenders. Perversely, corporate settings provide wrongdoers with a more persuasive explanation for their conduct than poor community settings provide for street offenders, and that explanation diffuses responsibility beyond the individual to a second responsible player. The literature on social norms

'"' Yet, it creates the prospect of a practical shift in liability that, in a limited sense, mimics a formal excuse. Corporate liability provides the government with another target for criminal liability in the firm, in addition to the agents-an alternative unavailable to street offenders. While the practice does not appear to be widespread, it allows for the firm instead of the individuals to be held liable.

"So' Michlel TONRy, MALign Neglect: Race, Criate, and Punishment in AMERICI 128-41 (1995) (outlining criminal defense patterns by race and social context); Sampson \& Wilson, supra note 17 , at 37 (providing inner-city criminal statistics). 
emphasizes that social influence explains much criminal conduct. ${ }^{12}$ Yet there is a practical barrier in that there is no organized entity, no legal-fiction person, to hold liable for the community's influence on street offenders. That is one of the few structural distinctions to explain the different treatment of comparable social influences on street and white-collar wrongdoing, even though such influence in the street context is clearly as strong, and thus as blameworthy, as in the corporate realm.

We could, however, take a lesson from corporate liability for street crime. While we cannot hold street offenders' communities or peer groups liable as entities, we can recognize the influence of those groups by devising other enforcement strategies that acknowledge the effect of social influence on street wrongdoing. ${ }^{93}$ We largely do not make such a recognition, however, and that distinction in practice between street and corporate enforcement leads us to repress social influence in the street crime context. The doctrinal distinction distributes liability differently among individuals in different settings who are subject to comparable social influence. Because we have no ready alternative, no legal entity, on which to spread blame, we downplay the significance of that influence and thus of responsible agents beyond the individual. Our operative conception of the street offender is of an atomistic, free-willed actor whose choices to commit crimes are her responsibility alone; the circumstances and influences that explain and predict her conduct are morally, as well as doctrinally, irrelevant. $^{94}$ In contrast, our moral-conceptual image of corporate wrongdoing builds on a premise of actors as social beings and acknowledges that culpability should properly be broader than the individual alone..$^{95}$ In this way, we construct a notion of street offenders as

${ }^{92}$ See Kahan, supra note 11, at 350; Tracey L. Meares, Place and Crime, 73 CHI.-KENT L. REv. 669, 669-70 (1998) ("[T]he structure of the community in which an individual lives interacts in important ways to either facilitate or retard that individual's criminal or delinquent behavior.").

${ }_{93}$ I discuss some nascent efforts and additional proposals in infra Part $V$ that fit this description.

${ }_{94}$ The U.S. Supreme Court made an analogous conceptual move in $M c C l e s k y ~ v$. Kemp, 481 U.S. 279 (1987). There, the Court accepted social science studies that found strong correlations between race, defendants, victims, and the imposition of the death penalty. Id. at 293. But because the defendant could not link the evidence of those patterns to how such bias actually occurred in his case, the Court deemed the evidence irrelevant for equal protection purposes. Id.

${ }_{95}$ For a terrific description of how allocations of responsibility depend upon alternative conceptions of the self that emphasize or repress social connections and context, see Dan-Cohen, supra note 65, at 968-77. For a practical example of how such alternative conceptions play out in public debate about criminal responsibility in 
more culpable because we emphasize their isolated individual choices and repress acknowledgment of any social influence.

Criminal law theory has occasionally toyed with the social depravity defense to recognize the reality of social influence on street offenders. The defense would allow one's guilt to be partially or fully excused because one came from a "rotten social background" in which social influence encouraging crime was widespread, social capital discouraging it scarce, and structural pressures toward committing it great. ${ }^{\text {th }}$ If we take social influence seriously, the defense poses the question whether we can judge individuals who come from communities that differ radically in the influence they exert for or against lawabidingness under the same standard.

We do indeed take such influence seriously sometimes. The empirical correlation of street crime rates in different communities with social capital indicators is irrefutable. Accordingly, it has become a much-touted basis for street crime prevention strategies. ${ }^{97}$ In the corporate context, social influence underlies not only corporate liability, but also charging leniency and sentence reductions for firms that discourage crime with formal compliance plans, representing efforts to shape social influence and capital. ${ }^{98}$ The U.S. Sentencing Guidelines provide corporations a substantial discount if, at the time of the crimes carried out by agents, they had in place an internal plan for minimizing law-breaking and maximizing regulatory compliance. ${ }^{99}$ In

corporate and street settings, see Franklin E. Zimring \& Gordon Hawkins, Crime, Justire, and the Savings and Loan Crisis, in BEYOND THE LAW: CRIME IN COMPLEX ORG.INIZ1TIONS 247 (Michael Tonry ed., 1993), which documents the widespread emphasis on structural explanations for savings and loans crimes in contrast to street crime offenses that emphasize individual moral choice.

'4' Compar' David L. Bazelon, The Morality of Criminal Law, 49 S. CAL. L. REV. 385, 389 (1976) (arguing that poor life circumstances should excuse crime), and Richard Delgado, "Rotten Sucial Background": Should the Criminal Law Recognize a Defense of Severe IEnvimmental Deprivation?, 3 J.L. \& INEQUALITY 9 (1985) (arguing for an excuse based on poor life circumstances), with TONRY, supra note 91 , at $134-48$ (responding to Delgadu and arguing against such an excuse), and Stephen J. Morse, The Twilight of Welfare Criminolog:: A Reply to Judge Bazelon, 49 S. CAL. L. Rev. 1247, $1251-52$ (1976) (arguing against such a life circumstance excuse).

"Sir mfra Part V (discussing the "broken windows" theory and community policingl.

Sir U.S. SENTENCING GUIDELINES MANUAL ch. 8, introductory cmt. (1998) ("Culpability generally will be determined by the steps taken by the organization prior to the offenve to prevent and detect criminal conduct ...."); Laufer, supra note 8, at 1386 (describing federal sentencing guidelines policies that provide discounts for compliance plans); Holder, supra note 66 (outlining factors to be considered in charging a corporation). 1389

U.S. SENTENCING Guidelnes MLANUAL \$8A1.2 (1998); Laufer, supra note 8 , at 
fact, corporations can gain an advantage if they merely devise such a plan after the crime-during the course of plea negotiations. "'(') Some critique the compliance-plan provisions as creating perverse responses. $^{101}$ The premise of these provisions, however, again enacts the social influence theory: one deserves less punishment if one tried to change positively the social contexts in which crime occurs because that social influence accounts for part of why actors opted to do crimes. As a crime prevention strategy, this is unremarkable. As a basis for adjusting culpability, it is unusual.

In practice, the social depravity defense is infeasible. As a practical matter, we cannot workably define "community" or "background" for purposes of the defense. Even if this were possible, the defense would perversely encourage unlawfulness precisely where we most need to discourage it. Further, the defense would force us to define the impossible lines of what Bernard Williams calls "constitutive luck"-the fortuities of birth and social life circumstances that greatly influence who we are and what we do. ${ }^{102}$ We must ignore much variation in luck to make any moral judgments at all, and we cannot fully compensate for variations before doing so. The question, then, is when and how much constitutive luck will play a role in responsibility ascriptions. Formally at least, criminal law, with some important exceptions, mostly ignores the social context in which an actor acts; ${ }^{11.3}$ it proceeds on the assumption of full autonomy to choose courses of conduct so that an actor can be judged morally blameworthy. ${ }^{1+4}$ In fact, as I argue below, we sometimes account for such social influences through enforcement discretion, but not in a way that diminishes the distinction between how we recognize it in street and corporate crime

${ }^{100}$ Laufer, supra note 8, at 1389-90; see also U.S. SENTENCING GUIDELINES MANUAL $\$ 8$ A1.2 (1998).

${ }^{101}$ Laufer, supra note 8, at 1405 (discussing the moral hazards and perverse incentives of compliance).

${ }^{102}$ BERNARD WILlIAMS, MORAL LuCK 20-22 (1981); Dan-Cohen, supra note 65, at 983.

${ }^{103}$ In addition to corporate liability, battered woman syndrome is arguably an example here, as are some emerging cultural defenses or culture-based mitigation evidence. See Holly Maguigan, Cultural Evidence and Male Violence: Are Feminist and Multiculturalist Reformers on a Collision Course in Criminal Courts?, 70 N.Y.U. L. REv. 36 (1995) (providing an overview of the debate on cultural defense in the case of battered woman syndrome).

${ }^{104}$ Kyron Huigens's recent work on a virtue ethics theory of criminal law suggests that we account for offenders' contexts and circumstances in the adjudication process, particularly in jury judgments, more than formal criminal law implies. See Huigens, supra note 1, at 1016-31. 
settings.

Corporate liability avoids the problems of the depravity defense by working as a supplemental form of liability rather than an affirmative defense. It may even give some offenders some of the benefits of a defense. Corporate liability adds another defendant to the mix of bargaining with the government, which can aid an individual, at least to the extent prosecutors forgo individual prosecutions to pursue the corporation or offer agents leniency in exchange for cooperation in the case against the entity. While prosecuting firms without also going after individuals is uncommon, bargaining is not.

More fundamentally, while corporate liability is a disadvantage for white-collar offenders because it makes additional liability possible, the doctrine ends up supporting an important conceptual distinction between street and corporate crime practice that works to the advantage of white-collar offenders. By positioning white-collar crime within a special space of criminal law that accepts social influence premises, corporate liability supports ideas about both the nature of offenders and of the crime that move white-collar practice away from the most punitive forms of criminal justice practice and toward a more civil, regulatory model of addressing wrongdoing and social harm.

\section{THE POLITICAL POIIER OF CONCEPTUAL DISTINCTIONS: DETERRENCE VERSUS RETRIBUTTVE RATIONALES}

\section{A. The Force of Retributivism and Deterrence Rationales}

The structural distinction of having a legal entity to stand for social context in commercial settings but not in street settings is one impetus for the greater emphasis on social influence in white-collar crime. But the conceptual distinctions implicit in corporate liability are more of a signal than a force for the divergence in street and corporate crime policy. That divergence is fostered by the rhetorical modes that dominate debate of these two criminal law sectors. Criminal law has long traditions of both retributivist and consequentialist premises. Street crime law maintains a relatively stronger emphasis on moral culpability and expressive condemnation. Corporate crime policy, in contrast, takes place more in a deterrence mode. This distinction in organizing rationales has significant implications for criminal justice policy choices. It supports a division that keeps street crime policy oriented toward dysfunctional models that emphasize criminal sanctions, while corporate crime policy is oriented toward a regulatory model in which criminal law plays a significant but supporting role. 
Consequentialist arguments have gained ground in criminal law, as they have in legal thought generally, in large part due to the rise of economic analysis. ${ }^{105}$ Dan Kahan has recently described how the opposed rhetorical modes of deterrence and expressive condemnation function politically in criminal law discourse. ${ }^{106}$ Deterrence serves to suppress the emotional and political content of criminal law's meaning, while expressive condemnation puts that content front and center, making it the object of heated political debate. Deterrence rhetoric cools passions-it sounds like rational policy talk. ${ }^{107}$ Expressive rhetoric heats passions-it is a tool in the battle over which political and moral values criminal law will serve. ${ }^{108}$

The deterrence-expressiveness modulation occurs not only through time, as political disagreement grows or diminishes with regard to criminal law; it also occurs across the landscape of substantive criminal law. Criminal law's unique feature is its moral expressiveness and the traditional background of thinking about criminal law's expressive meaning is street crime. The dominant responses for wrongdoing on the street are the death penalty, the wide support for imprisonment evident in longer sentences and prison construction rates, ${ }^{109}$ and the lower ages at which youthful offenders are punished as adults. In an earlier work, Kahan has described why alternative sanctions-for example, fines or community service instead of prison-are insufficiently expressive of the moral condemnation that society desires in a criminal judgment, and thus lack popular support as substitutes for prison. ${ }^{110}$ Sanford Kadish long ago worried that criminal law's expressive content would be diminished if applied to

${ }^{105}$ See Carol S. Steiker, Foreword: Punishment and Procedure: Punishment Theon and the Criminal-Civil Procedural Divide, 85 GEO. L.J. 775, 784-85 (1997) (exploring intellectual challenges to the civil-criminal distinction).

${ }^{106}$ See Dan M. Kahan, The Secret Ambition of Deterrence, 113 HARv. L. REV. 413 (1999).

${ }^{107}$ Id. at $427-35$.

${ }^{108}$ See id. at 419-35 (comparing expressive condemnation and deterrence principles).

Despite its origins as an institution designed to reform and rehabilitate offenders, see DAVID GARLAND, PUNISHMENT AND MODERN SOCIETY 157-92 (1990) (reviewing historical studies on the functions of imprisonment), the dominant contemporary purpose of incarceration is clearly to shame or to condemn, as well as to incapacitate, see Dan M. Kahan, What Do Alternative Sanctions Mean?, 63 U. CHI. L. REv. 591 (1996) (describing the social meaning of criminal punishments including prison terms, fines, and shaming sanctions).

${ }^{110}$ See Kahan, supra note 109, at 592 (explaining that the political unacceptability of alternative sanctions reflects their inadequacy along the expressive dimension of punishment). 
economic crimes. ${ }^{111}$ All this suggests that, while we use deterrence rhetoric sometimes in street crime discussions, an expressive and retributive moralism drives policymaking. Retributivism accords with the individualistic, autonomous view of street offenders, free of context, that we described in contrast to corporate liability premises. ${ }^{112}$

Corporate criminal law, in contrast, operates firmly in a deterrence mode. Corporate criminal law is part of an elaborate regulatory regime governing firms and commercial activity, and utilitarian thinking is the overwhelmingly dominant mode of analysis for administrative law. The deterrence framework has a couple of implications for corporate criminal law. The first is related to the one Kahan identifies more broadly-deterrence talk cools passions about the political content of corporate criminal law. ${ }^{113}$ It thereby helps to take political contention and moral outrage about such crimes off the table of public debate because it chills moral evaluation of wrongdoing in commercial settings. This is not to say, of course, that it is a foolproof means for doing so, as the savings and loan scandal of a decade ago boiled over into a public debate carried out in expressive idioms. ${ }^{114}$

Additionally, deterrence rhetoric implies that defendants are rational, reasonable actors who can be expected to respond sensibly to incentives. ${ }^{15}$ This is one reason why, for corporate wrongdoing, civil sanctions often seem appropriate substitutes for criminal sanctions. When all we are trying to do is deter bad conduct and foster socially desirable behavior, a civil fine can prompt a rational response from actors as well as a criminal one.

Yet the rational actor implicit in the deterrence model adopts in a subtle way the social-being view of corporate actors noted above. ${ }^{116}$ If

111 See SANFORD H. KADISH, The Use of Criminal Sanctions in Enforcing Economic Regulations, in BLLME AND PUNISHMENT: ESSAYS IN THE CRIMINAL LAW 40 (1987) (outlining the special characteristics of economic regulatory legislation relevant to the use of criminal sanctions and discussing their implications).

112 See supra text accompanying note 104.

11. Kahan, supra note 106, at 427-35.

11. For an overview of that debate, see Zimring \& Hawkins, supra note 95, at 247.

11. As noted above, however, regulation has moved to a more sophisticated model of human behavior that acknowledges, for instance, resentment and resistance to enforcement efforts. See supra note 75 and accompanying text.

"Ni" Note that the atomistic, free-willed actor model identified as the working premise for street offenders is not necessarily an assumption of a fully rational actor-that is on assumption sometimes used when talking about street crime punishments, such as prison or capital punishment, in deterrence terms. But we can just as easily assume street offenders are free-willed, yet irrational and driven by destructive passions and impulses. For them deterrence is ineffective, but moral blame is appropriate. 
we are dealing with rational actors who we nonetheless recognize as vulnerable to social influence, then the incentives we set up for them should include factors present in their social setting. Thus, while the incentives we impose on street criminals are traditional punishments that also carry expressions of moral opprobrium, the options for corporate actors expand to include the much wider array of civil regulatory tools that not only punish, as civil fines do, but also change the offender's social environment to make offending less possible and less likely. For instance, sanctions can take the form not only of traditional punishments like fines, but of voluntary pollution-reducing projects, ${ }^{117}$ reporting requirements, and other "enforced self-regulation"11* or "partial-industry intervention" mandates. "1" These strategies change how offenders do the activity that led to crime in the first place, and they change the environment in which it is done by increasing supervision. That there is little objection to the lack of expressive power in such sanctions as pollution-reduction projects speaks to how thoroughly deterrence concerns trump retributive ones for white-collar wrongdoing. Contrast the problem with the social meaning of criminal probation and community service that Kahan identified. ${ }^{121}$ Both are activities that good citizens, rather than criminals, do and so they imply no public shame or condemnation.

117 See Final EPA Supplemental Environmental Projects Policy Issued, 63 Fed. Reg. 24,796, 24,799-801 (May 5, 1998) (listing categories of acceptable supplemental environmental projects); Dana, supra note 44, at 1184-91 (describing substitution of "supplemental environmental projects" in lieu of fines as an EPA enforcement strategy'). A Bureau of Justice Statistics Special Report found that in 1997 the EPA negotiated 266 environmental projects with a total value of $\$ 85.4$ millon. John Scalia, U.S. Dep't of Justice, Federal Enforcement of Environmental Laws, 1997, Nov. 1999, at 3, available at http://www.ojp.usdoj.gov/bjs/pub/pdf/feel97.pdf. Relatedly, the EPA achieved injunctive remedies in 3735 actions that required elimination of noncompliant conduct and environmental restoration, estimated to value $\$ 1.9$ billion. Id.

${ }_{118}$ See, e.g., REES, supra note 33, at 9-10, 30-37, 154-71 (discussing self-regulation in workplace safety); Steinzor, supra note 68 (reviewing "reinvention" of environmental regulation, including self-regulation to replace "command-and-control" regulation).

${ }_{119}$ AYRES \& BRAITHWAITE, supra note 34 , at 101-57 (describing both self-regulation and partial-industry intervention).

${ }^{120}$ See Kahan, supra note 109 , at 591 ("[F]or those who commit serious criminal offenses, the law strongly prefers one form of suffering-the deprivation of liberty-to the near exclusion of all others."). 


\section{B. Shifting Enforcement from Judging Culpability to Fostering Compliance}

\section{Civil Sanctions and Culpability}

As the comparison of deterrence and retributive rationales discussed above suggests, when consequentialism dominates policies addressing wrongdoing and social harm, prevention and restitution goals take priority over judgments of culpability. Corporate regulation practice has responded to, and even led, scholarly literature critical of command-and-control punitiveness. ${ }^{121}$ Street crime regulation, with the exception of community policing strategies discussed further below, ${ }^{122}$ has been largely impervious to scholarly assessment or to reform strategies that have affected comparable areas of public policy.

An extensive regulatory regime to address corporate wrongdoing-civil and administrative fines, restitution orders, injunctions, and other forms of creative remedies-can take the place of criminal sanctions covering the same conduct and serving the same deterrence goals. ${ }^{1: 3}$ Agencies have even pushed the limits of statutory authority to innovate voluntary, nonpunitive remedies. ${ }^{12 *}$ The Justice Department's guidelines on prosecution of corporations explicitly adopt this view-adequate civil responses are a justification for forgoing criminal charges. ${ }^{12 .}$ Parallel statutory regimes providing civil and criminal sanc-

i/ Sre AIRES \& BRAITHWAITE, supra note 34, at 20 (arguing that regulators moved before scholars in seeing cooperative compliance strategies as superior to deterrence strategies based on punitive sanctions).

${ }^{12}$ Ste infra Part V.A (noting that community policing policies vary from punitive to cooperative in their approach).

This distinction was the basis for Edwin Sutherland's landmark work initially describing, and coining the phrase, white-collar crime. Sutherland complained that serious harms perpetrated by firms and high-status individuals were not labeled as deviant and were treated as regulatory rather than criminal matters, while comparable or lesser harms done by low-status people were considered deviant. EDWN $H$. SUTHERLIND, WHITE COLLAR CRME: THE UNCUT VERSION 7 (Yale Univ. Press 1983) (1949) (defining a "[w]hite collar crime ... approximately as a crime committed by a person of respectability and high social status in the course of his occupation"). Whitecollar criminal law has expanded dramatically since Sutherland's early work in the $14411_{s}$, but so has regulatory law. There still remains a huge body of civil and administrative law that applies to white-collar crime for which there is no parallel for street crime.

":" Se' Farber, supra note 42, at 310-11 (describing the EPA's "supplemental environmental project" settlements, used in lieu of monetary penalties, as an example of a practice that "seem[ed] dubious at the time in formal terms" but was subsequently "partially ratified by Congress").

72. Sec FCA GUIDANCE, supra note 59, at 460-61 (suggesting that Justice Department attorneys should consider alternative remedies before instituting civil fraud actions against health care providers and other corporate offenders); Holder, supra note 66, at 
tions for essentially the same conduct exist in virtually every area of white-collar wrongdoing, including health care fraud, ${ }^{126}$ environmental harms, ${ }^{127}$ workplace safety, and securities law. ${ }^{128}$ This is so despite the fact that, contrary to industry arguments, many white-collar criminal statutes govern conduct that unambiguously fits the traditional character of crimes. ${ }^{129}$ Health care fraud, money laundering, tax crime, and environmental statutes, for example, all have strong scienter requirements that prevent conviction for innocent conduct or for honest mistakes arising from unclear regulatory requirements. ${ }^{1,4}$ Statutes governing health care fraud typically require either knowledge of false or fraudulent conduct or "willful" conduct, an element that has been read to require proof that the offender knew that the conduct was illegal. ${ }^{131}$

Part II.A.8 (noting that the adequacy of noncriminal remedies should be considered when conducting an investigation into corporate conduct).

${ }^{126}$ Timothy S. JOST \& Sharon Davies, MEdicare aNd MEdicaid Fraud ind ABUSE $\$ \S$ 2-2, 2-3, 2-5 (2001-02 ed. 2000); see also 31 U.S.C. $\$ 3729$ (1994) (articulating civil penalties for defrauding the government); 42 U.S.C. $\$ 1320$ a-7(a) to (b) (1994 \& Supp. III 1997) (articulating the felony provision for willful fraudulent conduct in the health care context).

127 Dana, supra note 44, at 1184; see also EPA, ENFORCEMENT AND COMPLIANCE ASSURANCE ACCOMPLISHMENTS REPORT FY 1996, at 2-7 (1996) (documenting great use of civil penalties in settlements); Robert W. Adler \& Charles Lord, Environmental Crimes: Raising the Stakes, 59 GEO. WASH. L. REv. 781, 791-95 (1991) (summarizing key criminal environmental statutes).

${ }^{128}$ See United States v. O'Hagan, 521 U.S. 642 (1997) (holding that a person who trades in securities for personal profit, using confidential information misappropriated in breach of a fiduciary duty to the source of the information, is guilty of violating $\$ 10$ (b) and Rule $10 \mathrm{~b}-5$ of the Securities Exchange Act); Lynch, supra note 2, at 23-24 (" $[\mathrm{I}] \mathrm{n}$ cases arising under the securities laws ... there is often no distinction between what the prosecutor would have to prove to establish a crime and what the relevant administrative agency or private plaintiff would have to prove to show civil liability.").

${ }^{129}$ For examples of such industry arguments regarding health care fraud crimes and a response to them, see Jost \& Davies, supra note 29 ; in the context of financial crime, see Zimring \& Hawkins, supra note 95.

130e, e.g., Ratzlaf v. United States, 510 U.S. 135 (1994) (holding that the money laundering statute, 31 U.S.C. $\$ 5322$ (1994), requires knowledge that the act is unlawful); Cheek v. United States, 498 U.S. 192, 201 (1991) (holding that the federal tax evasion statute, I.R.C. $\$ 7201$ (1994), requires proof that the defendant intentionally violated a "known legal duty"); United States v. Ahmad, 101 F.3d 386, 391 (5th Cir. 1996) (holding that "knowing" mens rea of a Clean Water Act felony provision, 33 U.S.C. $\$ 1319$ (c) (3) (1994), applies to every element of the crime); Hanlester Network v. Shalala, 51 F.3d 1390 (9th Cir. 1995) (holding that the Medicare anti-kickback statute, 42 U.S.C. $\$ 1320 \mathrm{a}-7 \mathrm{~b}(\mathrm{~b})$ (1994), requires proof of knowledge of the law); Davies, supra note 83 , at $342-49,361-96$ (discussing willfulness requirements in these and other federal statutes).

${ }^{131}$ Jost \& Davies, supra note 29, at 293-305; see also Hanlester Network, 51 F.3d at 1400; Davies, supra note 83, at 343-47. 
These parallel regimes for white-collar wrongdoing stand in sharp contrast to the enforcement options available for street wrongdoing, and that difference has led to distinct approaches to enforcement discretion for conduct in each realm that could be prosecuted criminally. The disparate approaches greatly affect whether knowing or willful conduct that can be prosecuted criminally actually will be prosecuted. Much of the practice of enforcement discretion hinges on deterrence and restitution concerns. Prosecutors and regulators rarely let significant, knowing violations go without any response, but a response need not be a criminal sanction if civil alternatives exist. The factors used in the Justice Department's corporate prosecution guidelines spell out how private prevention strategies, such as firm compliance plans, and civil sanctions can justify forgoing criminal prosecution. $^{1.12}$ In health care fraud, the Justice Department explicitly urges alternative remedies before seeking civil liability under the False Claims Act ("FCA"),", and it overwhelmingly uses civil FCA liability instead of criminal statutes covering the same conduct. ${ }^{1.44}$ The same is true in the environmental context, in which civil fines far outnumber criminal fines, voluntary settlements recently have become common in lieu of some civil fines, and U.S. Attorneys decline prosecution at much higher rates than for other wrongdoing. ${ }^{135}$

When consequentialist concerns drive enforcement discretion even for conduct that, within the criminal law's terms, merits a decla-

is Ste Holder, supna note 66 (suggesting that prosecutors weigh the adequacy of noncriminal approaches prior to pursuing criminal charges).

1.4 FCA GUIDANCE, supra note 59, at 460-61.

1.1 Jost \& Davies, supra note 29, at 285, 306-12 (describing civil and criminal sanctions for false claims and discussing why the government often settles civil cases for well below statutory penalty amounts).

"For a discussion about environmental settlements between polluters and the EPA, see Dana, supra note 44, at 1185-91. As for prosecutorial declination rates, in 1997, U.S. attorneys declined to prosecute $61 \%$ of matters investigated for environmental protection offenses. Scalia, supra note 117 , at 4 . The declination rate was $70 \%$ far organizational suspects and $55 \%$ for individuals. Id. In contrast, the overall declination rate for matters investigated by U.S. attorneys was $27.2 \%$ (with wide variation for categories of crime: $18.1 \%$ for drug crimes, $33.0 \%$ for violent crimes, and $63.9 \%$ for regulatory offenses). BUREAU OF JUSTICE STATISTICS, U.S. DEP'T OF JUSTICE, Federal Criminal CASE PRocessing, 1998: WITH TRENDS 1982-98, at 8 tbl.2 (1999), http://www.ojp.usdoj.gov/bjs/pub/pdf/fccp98.pdf. This broad comparison can be only suggestive. Cases are declined for many reasons, and such a range in declination rates might be explained in part by the various environmental matters investigated as compared to other matters, such as drug cases. It may be, for example, that evidence is weaker generally in environmental cases than in drug cases, justifying more declination on those grounds. The Bureau of Justice Statistics data cited here give no basis for assessing those possibilities. 
ration of moral culpability, retribution becomes merely one concern that can be outweighed by others. Criminal law has a deterrent role, but compared to well-developed administrative law regimes it looks like a pretty crude means to encourage compliance. It is easy to see how appealing civil options can be for deterrence. We use criminal law for utilitarian ends only because we have not fashioned civil alternatives. ${ }^{136}$ When civil alternatives exist, the downsides of criminal law, such as costly procedural burdens, the stigmatizing effects that imperfectly match views of culpability, and the resentment that undercuts commitment to compliance, become more acute. Within much of white-collar practice, we preserve criminal law for the most egregious instances of knowing and harmful conduct-those in which the retributive and expressive function of criminal law become clearly necessary. ${ }^{137}$ This explains the criminal law's continuing, and even growing, role in white-collar contexts in the last two decades, even as the trend in regulation overall has been toward minimizing punitive, command-and-control strategies. ${ }^{138}$ As a broad generalization, policy on white-collar wrongdoing has remedied its deficiency of too little criminal law for culpable conduct-Sutherland's original point half a century ago ${ }^{139}$ - while at the same time moving toward a nonpunitive strategy of prevention and enforcement dominated by civil law. ${ }^{140}$

Offenders' wealth plays a role in shaping this dynamic. Whitecollar offenders are generally wealthier. As a consequence, whitecollar criminals are harder for the government to pursue because they

${ }^{136}$ In theory, either form can deter equally, but civil sanctions come without the burdensome procedural requirements of criminal adjudication. For examples of utilitarian arguments that suggest that civil sanctions fully substitute for criminal sanctions, see Fischel \& Sykes, supra note 87; V.S. Khanna, Corporate Criminal Liability: What Purpose Does It Serve?, 109 HARV. L. REv. 1477, 1497 (1996).

${ }^{137}$ Yet even for this purpose, civil alternatives compete. See infra Part V (demonstrating the contingency of criminal sanctions even for culpable past conduct). This is not to say that white-collar statutes do not criminalize some conduct that is marginal in terms of moral culpability. My point here is a broad generalization that emphasizes white-collar contexts in which there is also an extensive civil or regulatory regime. For an argument that white-collar statutes criminalize much conduct that is arguably innocent or marginally culpable, see William J. Stuntz, Substance, Process, and the CirilCriminal Line, 7 J. CONTEMP. LEGAL ISSUES 1, 13-14, 32 (1996).

${ }^{138}$ See, e.g., Adler \& Lord, supra note 127, at 790 (noting the increased use of criminal prosecution for environmental violations since the late 1980s and urging further use); Mark A. Cohen, Corporate Crime and Punishment: An Update on Sentencing Practice in the Federal Courts, 1988-90, 71 B.U. L. REV. 247 (1991) (discussing increases in corporate sentencing).

${ }_{139}^{139}$ Sutherland, supra note 123.

${ }^{140}$ See Laufer, supra note 8, at 1344 n.1, 1382-86 (noting that large firms overwhelmingly face civil and administrative, rather than criminal, proceedings). 
can raise enforcement costs with vigorous legal defenses starting early in investigations. ${ }^{11}$ Also, as William Stuntz has noted, wealth buys privacy, which greatly raises enforcement costs. ${ }^{142}$ Yet wealth also makes people and entities open to regulations and sanctions other than traditional criminal punishments. ${ }^{143}$ Wealth thus gives enforcement officials more choices for responding to wrongdoing.

Even when white-collar conduct is culpable, enforcement officials are less compelled to enforce criminal laws against lawbreakers who can make full restitution for substantial harms and who can be deterred by big fines and other serious civil sanctions, such as defendantfinanced monitoring of future behavior or license suspension. When the utilitarian functions of criminal law are fulfilled by civil alternatives, and some moderate expressive-blaming component is part of the civil remedy-for example, punitive fines or public acknowledgment of violation-the pressure for criminal sanctions diminishes. ${ }^{144}$ In this sense, criminal culpability is contingent on civil alternatives to criminal law. The key arguments left for criminal punishment-retribution or expressive condemnation-are undermined by regulators' sensitivity to consequentialist concerns, such as the alienating, resentmentfostering effects of punishment that reduce future compliance and cooperation.

For street crime, offenders' relative (or literal) poverty makes civil remedies that diffuse the need for criminal sanctions seem much less available. Poor people typically cannot make restitution, pay substantial fines, or finance monitoring of their future conduct. ${ }^{145}$ Civil forfeiture now plays a large role in more lucrative forms of street crime,

in St' generally KENNETH MLANN, DEFENDING WHITE-COLLAR CRIME: A PORTRAIT OF ATTORNEIS AT WORK (1985) (describing major themes in white-collar defense, including providing strategies and understanding clients).

${ }_{72}$ Stuntz, supra note 24, at 1823-24; see also William J. Stuntz, The Distribution of Frumth imrudment Privac, 67 GEO. WASH. L. REV. 1265 (1999) (noting that the law affords a graded protection of privacy, especially with respect to wealth).

"Examples of other regulations include professional license revocations or prohibitions from lucrative business markets, such as government contracting in the deferne or health care sectors. For a description of a recent example, see Kurt Eichenwald, HCA to Pay $\$ 95$ Million in Fraud Case, N.Y. TIMES, Dec. 15, 2000, at Cl (noting that being barred from participation in Medicare is automatic for firms convicted of defrauding the program). Other sorts of sanctions include reputational injuries and public shame that arise from public knowledge of wrongdoing. On shame in whitecollar contexts, see Dan M. Kahan \& Eric A. Posner, Shaming White-Collar Criminals: A Proposal for Reform of the Federal Sentencing Guidelines, 42 J.L. \& ECON. 365 (1999).

${ }^{11}$ Khanna, supra note 136, at 1509; Mann, supra note 3, at 1864-73.

15. An example of such monitoring could be electronic surveillance from an ankle bracelet, which courts typically make defendants finance. 
especially drug crimes, but it does not match the efficacy of civil and administrative alternatives for corporate conduct. ${ }^{1.6}$ In addition, its draconian severity seems designed more to punish and alienate than to remedy. ${ }^{147}$ Street offenders' poverty indirectly increases the perceived need for criminal condemnation by limiting alternatives to it.

\section{Social Costs as Mediators of Sanction Options}

Deterrence goals are not the only consequentialist concerns that factor into enforcement decisions and distinguish policy choices in white-collar and street settings. Recall the significant social costs that always accompany criminal punishment, and some white-collar civil sanctions as well, that are imposed on offenders and third parties in their communities. ${ }^{148}$ These social costs differentially affect prosecution decisions. In white-collar contexts, such as health care fraud, the government explicitly weighs not only deterrence goals and the offender's knowledge or harm she caused, but also the impact that punishment may have on those linked to the offender, such as communities served by a health care provider who committed fraud. ${ }^{1 "}$ Similarly, prosecuting a corporation for environmental or workplace safety, price-fixing, or accounting fraud ${ }^{150}$ will have recognized, and politically salient, collateral effects on workers, local communities, or shareholders. These social costs counsel for civil rather than criminal sanctions, or against greater rather than lesser penalties. ${ }^{151}$

The social cost concerns in white-collar crime enforcement are legitimate, but comparable ones in street crime enforcement get much less recognition and thus mediate enforcement policy less. Fagan and

${ }^{146}$ For a critical description of current forfeiture practices, see Eric Blumenson \& Eva Nilsen, Policing for Profit: The Drug War's Hidden Economic Agenda, 65 U. CHI. L. REv. 35 (1998).

${ }^{147}$ Id. at 81-82; see also United States v. Ursery, 518 U.S. 267, 315 (1996) (Stevens, J., concurring and dissenting) (arguing that civil forfeiture of claimant's home for growing marijuana is "punishment" under the Double Jeopardy Clause); Austin v. United States, 509 U.S. 602, 621-22 (1993) (explaining that civil forfeiture can be "punishment" under the Excessive Fines Clause).

${ }^{148}$ See supra Part I.C (discussing the importance of acknowledging social capital's impact in the context of criminal sanctions).

${ }^{149}$ FCA GUIDANCE, supra note 59, at $460-61$; Jost \& Davies, supra note 29 , at 285 , 312.

${ }^{150}$ See Norris \& Henriques, supra note 20 (describing guilty pleas in the "largest and longest accounting fraud in history, continuing at least 12 years and costing investors $\$ 19$ billion").

${ }_{151}$ Holder, supra note 66; see also Alexander, supra note 58 (describing the social costs to third parties of corporate crime). 
Meares, among others, have documented the extensive injuries to communities from aggressive criminal prosecution coupled with long incarceration policies. For example, families dependent on offenders for income or child care lose providers, offenders lose future employment prospects due to prison records, and communities lose the social capital that is the most effective tool for crime prevention and fighting poverty. ${ }^{152}$ Fagan and Meares have pointed out that community members confront these costs by mediating their "multiple roles" and "linked fate" with offenders-they suffer both from offenders' crime and punishment, so they may resist harsh punishment as the worse of two harms. ${ }^{133}$

The offenders' wrongdoing in corporate and street settings cannot be distinguished on retributivist grounds; many offenders in both sectors commit knowing or willful violations that cause substantial harm. ${ }^{1.4}$ Instead, it is other factors, including civil alternatives and the recognition of social costs, that explain distinct enforcement practices. Criminal liability is contingent on its alternatives, as well as on the political salience of the ancillary costs of punishment.

We miss the salience of the costs that Meares describes in part because we downplay the connection between street offenders and their communities compared to corporate agents and their firms, or even firms and their market sectors. The ignorance of this connection skews utilitarian analyses of the effects of punishment.

Notice, for example, that the social costs of street crime enforcement on communities work, in a limited sense, as an equivalent of corporate liability. We risk generating the same perverse effects as firm liability sometimes can. Jennifer Arlen has described how corporate liability can undermine deterrent efforts aimed at firms. ${ }^{153}$ Arlen argues that corporate liability could lead firms to lessen their own ef-

I': Fagan \& Meares, supra note 27, at Part IV; see also supra Part I.C.

17. Se Fagan \& Meares, supra note 27, at Part IV (discussing why African-Americans in particular have multiple reasons to hold complex views about the increase in puni-hment); ser also Meares, supra note 92, at 669-70 (noting that community-level structures mediate individual factors often connected with crime); Stuntz, supra note 24, at 1797 (discussing Meares's analysis and survey data showing that African-Americans oppose both drug legalization and harsh enforcement policies).

iit It is easy, in fact, to calculate greater harm from extensive fraud, pollution, or workplace dangers than drug use and distribution, burglary, or car or property theft.

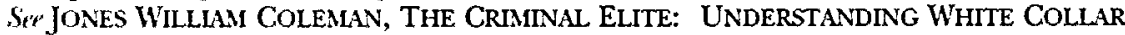
CRIME 9 (1998) ("The crimes we do know about are so huge, and their consequences so devastating, that they dwarf any known street crimes."); TONY G. POVEDA, RETHINKING WHITE-COLLAR CRIME 10-15 (1994).

Skt Arlen, supra note 88 , at 833 . 
forts, which include enforcement costs for the firm, to detect their agents' wrongdoing because they may end up paying more in criminal fines and enforcement costs than they save by preventing crime with rigorous monitoring efforts. ${ }^{156}$ We can view a community's noncooperation with law enforcement, for reasons of linked fate and the law's diminished legitimacy, similarly. Through noncooperation with police, community members may reduce their total losses. They gain more by nonenforcement, which occurs when they do not help police, because it reduces their social costs of punishment, than they lose by not helping police punish offenders, which raises the costs of crime. This does not mean, however, that community members are sanguine about wrongdoing in their communities. They likely would prefer a prevention strategy with more legitimacy and fewer social costs that reduces the incidence of wrongdoing: something, perhaps, on the model of less punitive, compliance-oriented strategies that regulate corporate activity.

The choice to prosecute culpable wrongdoing, then, turns in large part on two consequentialist concerns-whether civil sanctions exist that serve deterrence aims well and whether the social costs of punishment register politically and can be lessened by use of civil remedies. Enforcement officials weigh utilitarian concerns against retributivist ones in decisions to pursue or even devise enforcement options. But there is another aspect of this dynamic. Street offenders face criminal sanctions more often, and thereby are characterized not merely as wrongdoers but blameworthy actors, because of the paucity of civil means to address street wrongdoing. The choice of enforcement options helps shape views of conduct as more or less culpable. Culpability itself is not simply a stable factor weighed against utilitarian concerns, but an assessment dynamically constructed by punishment practice and the culture of which it is a part.

\section{G. The Meaning of Enforcement and Punishment Strategies}

What does it mean that willful conduct prohibited by felony criminal statutes, which causes substantial harm and for which the government has no evidentiary problems, is nonetheless pursued by the government solely as a civil action or resolved in a civil settlement? Much white-collar wrongdoing is conduct that the government has an affirmative, justified reason to punish criminally. Prosecutorial decli- 
nation is a species of lawmaking with expressive effects. ${ }^{157}$ Yet because discretion is used differently in white-collar and street settings, it has different expressive effects, different meanings, in each context for the public, the offender class, and even enforcement officials.

Widespread handling of conduct as civil when it is eligible for criminal prosecution negates the public view of the conduct as criminally culpable. As a consequence of the law's educative function, the public gets the signal that such civilly sanctioned wrongdoing is not as blameworthy as real crime that must be dealt with criminally. Willful white-collar wrongdoing comes to seem less criminal, while street wrongdoing, always prosecuted criminally, comes to seem more so. Offenders do not acknowledge the moral culpability of their actions, and they develop expectations that certain conduct will not be treated criminally even though it is covered by a criminal statute. Hence, defense attorneys regularly argue to prosecutors that their clients should not be indicted because their conduct was not really a crime, and prosecutors sometimes agree. ${ }^{158}$ Civil liability signals blameworthiness only in a limited civil law sense that one must accept responsibility for harm caused. Civil sanctions can be extensive and punitive, but they lack the expressiveness of criminal culpability.

In this way, our practices of judgment and punishment communicate and help actively construct the meaning of the conduct and harms they address. David Garland's description of how traditional criminal punishments work as cultural agents explains our regulatory responses to corporate wrongdoing. Sanction practices, Garland writes,

are one part of an authoritative, institutional discourse which seeks to organize our moral and political understanding and to educate our sentiments and sensibilities.... Through their judgments, condemnations and classifications they teach us (and persuade us) how to judge, what to condemn, and how to classify.... [T] he practices, institutions and discourses of penalty all signify, and the meanings which are conveyed thereby tend to outrun the immediacies of crime and punishment and

${ }^{17}$ Ser' Stuntz, supra note 137, at 28 (explaining that the prosecutor is "a lawmaker, not a law taker"). It is widely' accepted, for instance, that adultery will not be prosecuted and thus is not perceived as a crime, even though many states still have statutes criminalizing it. See id. at 34-35 (comparing sodomy laws and marijuana possession as criminal prohibitions that "forbid behavior that is not treated as criminal, even by police and prosecutors," with some traffic offenses that are widely enforced because they are "functionally civil").

ILANN, supra note 141, at 192-200; Lynch, supra note 2, at 23-26. 
'speak of' broader and more extended issues. ${ }^{159}$

Enforcement strategies and punishment practices likewise construct and regulate our understanding of street crime and the responses that seem compelled by it. Used much more extensively for street wrongdoing, criminal punishment reinforces the view that such conduct is so blameworthy that only criminal sanction is appropriate. These cultural, educative influences affect perceptions of both the public and enforcement officials so that punitive strategies become the default response to street crime, while civil remedies dominate corporate crime. ${ }^{160}$ The distinctive practices become self-reinforcing. The meanings of enforcement practices affect not only negotiations between prosecutors and defense attorneys about charging, as noted above, but also shape public debate. ${ }^{161}$ They make many of us more receptive to arguments that dispute the appropriateness of criminal punishment even for very harmful wrongdoing in corporate settings, and of less punitive alternatives in street contexts.

A prime example comes from the public debate regarding the savings and loan crisis of the late 1980s. In an argument that one cannot imagine gaining an equivalent level of prominence about street crime, "the failure of the regulatory system [was] widely seen as a principal cause of large-scale criminal conduct." ${ }^{\text {"62 }}$ One top regulator said, "I suppose bad members of the industry are at fault, but they are at fault because the government allowed them in. The government said here's the candy .... and then call[ed] off supervision ... [to] create almost an entrapment-a fatal attraction ...."163 Zimring and Hawkins noted that "many observers ... speak of regulatory changes as a proximate cause of a wave of financial recklessness quite frequently including criminal conduct.... [and] that this was one crime wave that was made in Washington."

In addition, public explanations for the savings and loan debacle are a good example of how a tradition of civil regulatory enforcement, rather than punitive criminal enforcement, shapes understandings of wrongdoing that support those divergent strategies. Civil regimes with little morally expressive content foster understandings of wrongdoing

159 GARLAND, supra note 109 , at 252-53.

${ }^{160} I d$. at 262.

161 See supra text accompanying note 158.

${ }^{162}$ Zimring \& Hawkins, supra note 95, at 281 (emphasis added).

${ }^{163} I d$. at 282 (quoting William Seidman, the Federal Deposit Insurance Corporation Chairman) (citation omitted).

${ }^{161}$ Id. 
in structural terms-in terms of being influenced and partly explained by a poorly administered social or regulatory environment. The moral judgment implicit in criminal law, in contrast, necessarily implies individual moral failing that suppresses social context explanations. By characterizing the causes of wrongdoing differently, we revise assessments about the degree of blameworthiness of particular conduct, just as by choosing one deterrence mechanism-civil sanction-over another-criminal sanction-affects views about how much retribution offenders deserve.

In contrast, consider the widely publicized strategy by prosecutors in at least two dozen states in the 1990 s of prosecuting mothers of babies exposed to cocaine in utero. ${ }^{165}$ While the policy had its opponents, led by the American Civil Liberties Union and scholars such as Dorothy Roberts, enforcement officials stressed the need for the "very firm stick" of criminal prosecution to coerce drug treatment, including a no-drop prosecution policy for second drug test failures. Judges sentenced some women to several years in prison. ${ }^{166}$ Structural influences, or even the mother's drug addiction, played no mediating role in descriptions of this public health problem, even though this aspect of street crime-drug use-is one for which we have at least smallscale models for successful, civil remedies. ${ }^{167}$

One implication of these examples is how the practice of enforcement affects views about the degree to which particular conduct is culpable. That is, what distinguishes white-collar from street enforcement is not only that we take different account of social costs in each sector, but also how we balance those costs with deterrence goals and the need to label culpability. We support the shift of civil alternatives by reducing the culpability assessment of the wrongdoing itself so that it weighs less heavily in that overall assessment. Ranking different offenses on a moral scale of blameworthiness is inevitably imprecise and contentious, ${ }^{16 x}$ but enforcement practices help make some conduct just seem so bad, while other actions seem, almost viscerally,

"1". Roberts, supra note 82 , at 938 . For a highly critical analysis of these prosecutiuns, see Dorothy E. Roberts, Punishing Drug Addicts Who Have Babies: Women of Calor, Equalit;, and the Right of Privacy, 104 HARV. L. REV. 1419 (1991). But see KENNEDy, supra note 25, at 353-63 (criticizing Roberts's analysis).

Roberts, supra note 82, at $941-45$.

11.7 St't iufra Part V.B (discussing drug treatment courts). The public was receptive enough to this approach to elect the local prosecutor who campaigned on this strategy as the state's attorney general. Roberts, supra note 82 , at 945 .

itis St' Stuntz, supra note 137, at 30 (arguing that there is "no good metric" for deciding "what offenses do and don't deserve criminal status"). 
much more so. ${ }^{169}$ Acknowledging environmental influences frames conduct in a manner that makes it easier to view the conduct as deserving less blame. Being part of a larger regulatory environment makes it easier to see white-collar crime as a product of structural influences rather than as merely bad actors whose moral failings alone explain crime. ${ }^{170}$ Here we can see how the earlier description of corporate liability, with its implicit acknowledgment of social context as a cause of corporate crime, is in accord with this analysis.

\section{The Implications of Structural Thinking and the Contingency of Culpability}

Recognizing structural pressures on conduct sharply changes enforcement strategies. It prompts legal responses to wrongdoing that reduce the opportunity for crime; we change the actor's context to make crime less possible. Thus, for corporate wrongdoing, we see an array of remedies imposed for past wrongdoing that are essentially structural changes with preventive goals. Offenders, or merely anyone engaged in a given activity, may have to report their conduct, be it environmental discharge of waste or financial transactions. ${ }^{171}$ Or, offenders may have to agree to business structures that prevent future collusion. These sorts of legal responses, common in regulatory law and arising from deterrence frameworks, focus little on blame and much on reducing opportunities for recurrence of wrongdoing.

Criminal law's responses to street crime, on the other hand, do not emphasize restructuring a criminogenic setting, in large part because those changes are not in control of an individual offender or law enforcement officials, for the most part. Those responses are mostly characterized by punitive sanctions with retributive goals-focused on the individual wrongdoer who chose poorly in his conduct, rather than on conditions that encourage such choices. Even the progressive rationale for criminal sanctions, far from dominant today, aims for rehabilitation of the individual, rather than targeting the op-

${ }^{109}$ See William lan Miller, The ANatomy of Disgust (1997) (broadly describing the social construction of emotions, including responses of disgust); Dan M. Kahan, The Anatomy of Disgust in Criminal Law, 96 MiCH. L. REv. 1621, 1621 (1998) (suggesting the utility of Miller's thesis in criminal law).

${ }^{170}$ See Zimring \& Hawkins, supra note 95 , at 286-88 (discussing the triumph of structural explanations of theories of crime causation).

${ }^{171}$ For examples in environmental, occupational safety, and futures markets contexts, see Neil Gunningham, Beyond Command and Control: Towards Flexible and CostEffective Business Regulation, in BuSINESS, ETHICS AND THE LAW 93, 95-109 (C.A.J. Coady \& C.J.G. Sampford eds., 1993). 
portunities and influences for crime that surround him.

These distinctions between how we treat street and corporate wrongdoers are not driven by objective, inalterable differences in offenders and offenses, but by whether we emphasize moral autonomy or social influence in our view of the offender and her conduct. This choice informs our relative preferences for punitive or regulatory approaches to wrongdoing. As the arguments over the savings and loan crisis and drug crime policy show, we could just as easily describe drug offenders as products of criminogenic communities that call for structural, public health responses rather than punitive, criminal ones, while we view illegal savings and loan operators causing billions of dollars in harm as immoral actors for whom the primary response should be criminal punishment. Criminal law focuses us on an offender's character, while regulatory justice focuses us on the social harm that needs a remedy. Regulatory policy toward corporate wrongdoing helps sustain the premise that there is little wrong with corporate offenders' character. Context and influences they face lead some people of ordinary character to socially harmful conduct. Yet the absence of civil, regulatory, or other less punitive strategies is not compelled by street offenders' poverty nor by other structural barriers. We have failed to develop structurally oriented, less punitive approaches because enforcement practices limit our perceived range of options. The use of punitive criminal law to combat street crime builds and perpetuates ideological frameworks that support punitive approaches and take regulatory alternatives off the table.

There is no better example of this ideological tunnel vision than our response to the 900-pound gorilla of contemporary criminal dockets-drug cases. ${ }^{172}$ Analysts widely agree that drug crime, and the property and violent crime associated with it, can be more effectively and cheaply addressed with a public health strategy of treatment and prevention, backed up only secondarily by criminal sanctions with lower social costs, rather than through the current approach of punitive criminal enforcement as a default solution. ${ }^{173}$ We have segmented

17. Si" Key Crime $\$$ Justice Facts, supra note 77, at 2 ("Of cases concluded in Federal divtuict court in every year since 1989 , there have been more drug cases than other types of cases.").

15: A review of U.S. drug policy over the past decades finds a strategy characterized by an overriding focus on criminal sanctions.... We have refused to recognize any limits in criminal law by continuing to push for greater and harsher penalties in the mistaken belief that citizens can be frightened or shocked into giving up their insatiable drug habit.

Gregory H. Williams \& Sara C. Williams, America's Drug Policy: Who Are the Addicts?, 75 
drug enforcement efforts to focus on a portion of drug users and sellers who are disproportionately minority and poor, ${ }^{174}$ which feeds an image of drug criminals that further entrenches public preference for punitive approaches over civil and remedial utilitarian ones. Using criminal law to address even illicit drug use by addicts demonstrates how compelling the expressive need for criminal punishment seems as a result of its long practice. The behavior arising from addiction should be at least as easy to characterize with minimal emphasis on moral failure as savings and loan crimes. Thus, culpability is not an absolute value. Assessments of criminal blameworthiness are partly a function of the alternatives to criminal blaming. Culpability is a dependent variable.

Synonymous with savings and loans crimes or crack use during pregnancy, domestic violence is a good example of the social construction of moral culpability. Until recently, a classic battery committed by a spouse simply was not viewed as a crime. This same construction of what counts as crime extends throughout all harmful wrongdoing: crime is not crime due to any objective sine qua non such as harm, intent, or even, surreptitiously, the identity of the actor. Those factors do play a part, but larger contexts of culture and perspective arising from particular social practices greatly affect how we interpret those factors. This complex dynamic determines culpability. Then, as we have seen, culpability is merely one element that is weighed against consequentialist concerns in decisions whether to treat wrongdoing criminally.

The variability in whether we view wrongdoing as requiring criminal condemnation mimics our practice at the adjudication stage in legal interpretation. Mark Kelman has noted that applying statutes requires the implicit construction of a fact pattern, "characterized by interpretive constructs," that operates without conscious acknowledgment. $^{175}$ These interpretive choices have the effect of making "a

IOWA L. REV. 1119, 1130 (1990); see also, e.g., STEVEN B. DUKE \& ALBERT C. GROSs, AMERICA'S LONGEST WAR: RETHINKING OUR TRAGIC CRUSADE AGAINST DRUGS, at xviii (1993) (coming to the conclusion "that the costs [of the drug war] are not remotely" justified"); MichaEL MASSING, THE FIX 12-13 (1998) (proposing a new public health approach to the nation's drug problem); Michael Winerip, Why Harlem Drug Cops Don 't Discuss Race, N.Y. TIMES, July 9, 2000, at A1 (reporting that a police lieutenant who supervises a "buy-and-bust" drug enforcement team said, "[i]n my humble opinion, we're doing nothing up here").

${ }^{174}$ See Stuntz, supra note 24, at 1804-13 (describing differences in investigative efforts in upscale versus downscale drug markets resulting from the fact that downscale markets are much cheaper to investigate).

${ }^{175}$ Mark Kelman, Interpretive Construction in Substantive Criminal Law, 33 STAN. L. 
single legal result seem[] inevitable." ${ }^{\text {,76 }}$ Kelman argues that interpretive constructs in criminal law operate in several ways to unconsciously shape our view of a defendant's conduct. ${ }^{177}$ For example, we can choose to broadly or narrowly construct the relevant time frame. ${ }^{178}$ Sometimes events that occur before or after the offender's key conduct become relevant to judging an act as criminal. Similarly, we view a defendant's intent narrowly, looking solely to the physical actions at the moment of the alleged crime, or broadly, to include her goals and motives. ${ }^{174}$ Additionally, criminal law alternates between assessing an offender distinctly, as a particular individual with specific perceptions and capabilities, or more generically, as a person of normal capacities who fits widely held assumptions about human traits and abilities. ${ }^{180}$ Implicit in these choices of interpretive constructs are normative baselines defining which facts are relevant to understanding offenders' conduct and assessing culpability.

What Kelman has identified in statutory interpretation also operates throughout enforcement policy. In viewing crime in corporate settings more structurally, we frame such conduct in a manner that makes it easier to accept civil remedies over criminal sanctions, to lessen individual liability in exchange for corporate liability, and to ease corporate liability in exchange for promises of preventive structural reform, such as compliance plans. The relatively deterrencefocused mode for corporate crime, in contrast, restrains movement toward a dysfunctionally harsh corporate criminal policy that would match, say, the war on drugs. In contrast, we repress social and structural influences with street offenders and cabin our perspective in a way that facilitates punitive criminal tactics. The relatively expressive mode in which street crime law is understood represses the prospect of moving to alternative sanctions or noncriminal regulatory and policy approaches. ${ }^{1 \times 1}$

REV.591, 593 (1981).

iñt. In.

17 Id.

riv 1 . at $593-94$.

Id. at 595-96, 620-33; see also Lynch, supra note 2, at 42 (making a comparable point about unacknowledged narrow or broad framing of offenders' actions to make conduct seem more or less undesirable).

Kelman, supra note 175 , at $596,633-42$.

Note that federal criminal statutes have expanded in recent years to cover conduct also governed, and previously only governed, by civil law. We have had a modest but notable increase in the use of criminal law as a tool to deal with white-collar wrongdoing. One might offer lots of reasons for that shift-from the political ease with which Cangress now enacts tougher criminal statutes, to a gradual elimination of 


\section{E. Political Process Problems and Offenders' Influence}

Enforcement policy is set by political actors-executive branch officials and agencies-and the implicit choices creating the divergent paths of white-collar and street criminal liability are ultimately political ones. It is worth noting how this political outcome occurs when constitutional law makes a substantial effort to govern political bias against a classic discrete and insular minority, criminal defendants, who are likely to lose out in majoritarian political processes. We constitutionalized much of criminal procedure as a protection against political bias aimed at such out-groups. ${ }^{1 \$ 2}$ Criminal defendants seem to be an obvious out-group, not only because we expect the majority to have little sympathy toward criminal conduct, but because we usually think of offenders as being mostly poor and black. Yet it turns out that there are criminal defendants and there are criminal defendants. For traditional street offenders, who are disproportionately poor and minority, this political process analysis holds. For white-collar offenders, however, it does not. Moreover, as William Stuntz has shown in a series of articles, constitutional criminal procedure is not much of a protection against political bias without also constitutionalizing substantive criminal law. ${ }^{183}$ Legislators and police can avoid procedural re-

a former class bias, to the widening rich-poor income gap and growth of corporate entities-all of which may be fueling a modest anticorporate/populist backlash. The analysis here, however, suggests another possibility: growing criminalization is a byproduct of our shift in the last thirty years to a more retributive and punitive criminal justice system for street crimes and of the increasing use of criminal law over other social policy tools to address social problems. Drug use is the perfect example of such a problem. Drug use is a social problem that clearly could be dealt with effectively with a regulatory and public health approach - and briefly, three decades ago, was-but it has been demonized instead as morally condemnable criminal activity. See MASSING, supra note 173 (documenting public health approaches to drug addiction from the Nixon administration to the present day). Criminal law overall has become such an expression-loaded tool that the existence of criminal statutes governing white-collar activity must mean that such conduct deserves a harsh approach as well.

Although white-collar crime has followed street crime trends in the sense that there are some indicators of increased use of criminal law, and longer sentences, for corporate wrongdoing in the past two decades, the more important but less noticed comparison is the divergence in approaches to wrongdoing in these two sectors. The last three decades have seen a marked transition in thinking about regulation of firms and white-collar activity that emphasizes cooperation and deemphasizes punitiveness. In the street crime context, meanwhile, we have seen a steadily increasing move toward punitiveness and an ever-decreasing reliance on cooperative and compliance fostering strategies.

${ }^{182}$ See, e.g., Michael J. Klarman, The Racial Origins of Modern Criminal Procedure, 99 MICH. L. REV. 48 (2000) (describing the Supreme Court's early constitutional criminal procedure decisions as an effort to protect blacks facing Jim Crow justice).

${ }^{183}$ See, e.g., William J. Stuntz, The Uneasy Relationship Between Criminal Procedure and 
strictions by expanding substantive liability, giving police and prosecutors more discretion to investigate, charge, and bargain. For street offenders, this strategy has subverted the goals of constitutionalized criminal procedure. White-collar offenders, however, have had more success responding to the expansive substantive criminal law that they face. ${ }^{\text {in }}$ They have expansive civil and regulatory liability on their side. Furthermore, the majority of white-collar offenders are neither poor nor black. They are wealthy enough to have a political voice in the lawmaking and enforcement mechanism that governs them and to make the increased costs that criminal procedure impose on the government compared to civil procedure a significant factor. The upshot is a variation on the political process problem for criminal defendants: power and wealth help to get one's wrongdoing treated civilly, while political marginality means wrongdoing will likely be treated criminally."

Debra Livingston, Dan Kahan, and Tracey Meares have all argued that courts should relax constitutional governance of police enforcement when the communities being policed have a sufficient voice in the local political system and are able to influence substantially the discretionary enforcement choices by police. ${ }^{186}$ This relative increase

Criminal Justirf, 107 YALE L.J. 1, 6 (1997) ("Constitutionalizing procedure, in a world where substantive law and funding are the province of legislatures, may tend to encourage bad substantive law and underfunding. But constitutionalizing some aspects of ubstantive criminal law and defense funding would not tend to encourage bad procedure, or bad anything else.").

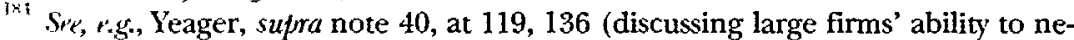
gotiate substantive pollution standards to which they will be held by regulators).

"Here my loose usage of the terms "white-collar" and "corporate" crime needs to be more precise. This claim about political voice is broadly true for corporate offender.. Sit, e.g., Peter C. Yeager, Law, Crime, and Inequality: The Regulatory State, in CRIME AND INEQUALITY 247 (John Hagan \& Ruth D. Peterson eds., 1995) (describing industry negotiation with regulators over what environmental standards must be met to be in compliance). Depending on one's definition of white-collar crime, however, it is less true. Some studies suggest that most offenders of crimes that can be labeled "whitecollar" are in fact nonwealthy, middle class people. See DAVID WEISBURD ET AL., CRIMIES OF THE MIIDDLE ClasSES (1991). Throughout this Article, I have tried to emphisize a subset of white-collar offenses, such as environmental, health care fraud, and financial fraud crimes, for which my thesis is most salient. I acknowledge, however, that many crimes that can plausibly be labeled "white-collar," such as false-statement crimes under 18 U.S.C. $\$ \$ 1001,1005$, and 1014 , can be and are committed by nonwealthy individuals.

Ste Dan M. Kahan \& Tracey L. Meares, The Coming Crisis in Criminal Procedure, 86 GEO. L.J. 1153, 1173 (1998) ("The political process theory tells courts not only when they should relax the standard of review, but also when they shouldn't."); Debra Livingston, Polic Discretion and the Quality of Life in Public Places: Courts, Communities, and the Nine Policing, 97 Colun. L. REv. 551, 660-61 (1997) ("By openly discussing the formulation of guidelines, police effectively announce in advance the approach to a problem 
in the local power of minority communities, a power that did not exist before the victories of the civil rights movement thirty-five years ago, is one example of how political power can regulate and inform criminal justice policy. That level of influence on some segments of justice policy-city ordinances and enforcement strategies-however, is only one piece of the larger criminal justice system, which in turn operates within a larger political dynamic. Local influence is not yet matched at other levels of political debate about criminal justice policy and its alternatives. While there is evidence that neighborhoods have enough political power to make police responsive to their desires, ${ }^{187}$ concern about, ${ }^{188}$ and evidence of, ${ }^{189}$ minority community distrust of police continues. This distrust stems from practices on other fronts, which range from racial profiling to draconian incarceration policies. Meares, for example, writes in support of broad ordinances checked by local influence on police and yet also about the loss of legitimacy that the criminal justice system faces in black communities due to punishment policies. ${ }^{190}$ Street crime offenders and the communities in which they live have much less influence in shaping policy and enforcement choices than white-collar offenders and corporations. Street offenders are disadvantaged in the political process, which permits enforcement officials to externalize the social costs of punitive enforcement policies. White-collar offenders, however, are much more effective at bringing those costs to the forefront of political debate and using them as an argument for enforcement alternatives.

that the department has tentatively decided to take. Police can obtain information from neighborhood residents or from advisory councils and the larger community about the acceptability of the planned approach.").

${ }^{187}$ See Kahan \& Meares, supra note 186, at 1167 (discussing how the citizens of African-American communities, for example, have been using their political power to obtain more effective law enforcement in the inner cities); Livingston, supra note 186 , at 654 ("This responsiveness and accountability to the community is particularly important in the context of police interventions aimed at restoring or preserving the quality of life in local neighborhoods.").

${ }^{188}$ See COLE, supra note 25 , at 5 (noting that poor and minority citizens are disproportionately victimized by crime); KENNEDY, supra note 25, at 157 (discussing racial profiling); Fagan \& Meares, supra note 27, at Part I ("The growth in incarceration... has been far greater for African-Americans than any other ethnic or racial group.").

${ }^{189}$ See Rosen, supra note 26 , at 54 (discussing whether white and black jurors are capable of transracial agreement).

${ }_{191}$ Meares, supra note 92, at 678; Fagen \& Meares, supra note 27.

191 See, e.g., Jost \& Davies, supra note 29, at 242-46 (describing the political backlash following a punitive approach to Medicare and Medicaid fraud); Yeager, supra note 185 , at 250 ("Potential white-collar or business defendants are commonly involved in the active shaping of the very legal definitions being applied to their behaviors by en- 


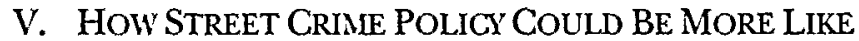 WHITE-COLLAR CRIME POLICY}

The implication of this analysis is that criminal and regulatory policy in both street and white-collar settings depends a lot more on things that we can change-descriptive interpretations of wrongdoing, recognition of social influences, the priority of retributivist or consequentialist goals, and development of a broad array of enforcement options-than on things we cannot-offenders' wealth, legal recognition of firms but not gangs or neighborhoods, or hard distinctions in types of offenders. Thus, street crime enforcement could take strides toward preventive, compliance-oriented, less punitive, regulatory strategies that we have devised for white-collar wrongdoing. It could take advantage of, rather than ignore and contradict, knowledge about social influence; it could more fully assess and minimize the social costs of punishment. Street crime policy could follow corporate regulatory policy by making criminal law an ancillary tool for prevention. This would be one means among several for confronting the most culpable wrongdoing, while a mix of less punitive strategies dominates policy.

In fact, we already have several models for some of the components of such a strategy. Most are small-scale, but nonetheless have sufficient track records of success to point the way toward reshaping street crime policies of enforcement and punishment. Even if all of these models were more widely implemented, there would still only be a very partial shift toward the corporate crime/regulatory model. Retributivism and command-and-control deterrence have dominated policy thinking on street crime for so long, without influence from the progress in corporate crime regulation, that these examples merely suggest the direction in which policy could move rather than map its details. Nonetheless, consider the following as sketches toward how such a regime could, in part, look.

\section{A. Community Policing}

The best known component of a transformed street crime policy is a subset of the strategies that compose community policing, which have garnered a lot of scholarly and political attention in recent years. A variety of approaches going by the label of community policing have been instituted in many American cities over the last fifteen years, in- 
cluding most of the largest. ${ }^{192}$ One approach, sometimes called ordermaintenance or problem-oriented policing, ${ }^{193}$ can take many forms, and its variation in part accounts for its mixed track record. ${ }^{194}$ Community policing is closely associated with the "broken windows" theory that urges police to focus on relatively minor "quality of life" problems that are associated with neighborhood disorder and foreshadow larger crime problems-these include loitering, aggressive panhandling, graffiti, and unsafe parks or vacant properties. ${ }^{195}$ The theory argues that by restoring order and a feeling of security among residents, police help reinforce informal social norms and influences that reduce serious crime. ${ }^{196}$ Yet, like criminal justice policy generally, community policing policies vary from aggressively punitive to cooperative approaches that emphasize local cooperation and prevention over zealous criminal enforcement.

Some versions of community policing, such as New York City's, take a more punitive form of aggressive misdemeanor arrest policies to enforce "zero tolerance" for conduct that contributes to social disorder. ${ }^{197}$ This approach reduces disorder; however, it can have heavy

${ }^{192}$ See The Challenge of Community Policing (Dennis P. Rosenbaum ed., 1994); TODD MCEWEN, NAT'L INST. OF JUSTICE, NATIONAL ASSESSMENT PROGRIM: 1994 SURVEY RESULTS 27 (1995) (finding that eighty-two percent of police chiefs polled have adopted some community policing strategies, and the remainder indicated a desire to adopt such strategies); WESLEY G. SKOGAN \& SUSAN M. HARTNETT, COMMUNITY POLICING, CHICAGO STYLE 5 (1997) (evaluating community policing efforts in Chicago); Jonathan Eig, Eyes on the Street: Community Policing in Chicago, AM. ProspeCT, Nov.-Dec. 1996, at 60, 61 ("[C]ommunity policing is ubiquitous.").

${ }^{193}$ See Livingston, supra note 186 , at 558-59, 573, 575 (defining order-maintenance policing as helping to refocus attention on problems of neighborhood disorder).

${ }^{194}$ Eig, supra note 192, at 64-66 (describing scholarly assessments that "community policing failed in New York [City]," but seems more successful elsewhere, including Chicago, Portland, and San Diego, due to long-term political leadership, "commitments of funds[,] and institutional change" within police departments).

${ }^{195}$ See James Q. Wilson \& George L. Kelling, Broken Windows, ATLANTIC MONTHLY, Mar. 1982, at 29 (articulating the "broken windows" theory); see also James Q. Wilson \& George L. Kelling, Making Neighborhoods Safe, ATLANTIC MONTHLY, Feb. 1989, at 46, 48 [hereinafter Wilson \& Kelling, Making Neighborhoods Safe] ("If the first broken window in a building is not repaired, then people who like breaking windows will assume that no one cares about the building and more windows will be broken.").

${ }^{190}$ See Kahan, supra note 11 , at 367-77 (discussing order maintenance as a law enforcement strategy); Livingston, supra note 186, at 573-91 (discussing the positive effects of community policing on neighborhood safety).

${ }^{197}$ See Bernard E. Harcourt, Reflecting on the Subject: A Critique of the Social Influence Conception of Deterrence, the Broken Windows Theory, and Order-Maintenance Policing New York Siyle, 97 MICH. L. REv. 291 (1998) (criticizing New York's version of community policing as overly aggressive and punitive); Jeffrey Rosen, Excessive Force, NEW REPUBLIC, Apr. 10, 2000, at 24-27 (describing the shift in New York's community polic- 
legitimacy costs. The strategies that more effectively move street policy to a regulatory model aim to involve officers in ongoing cooperative alliances with local citizens to engage in proactive activities to reduce crime by improving neighborhood order and quality of life.

For example, police in Newport News, Virginia, helped to substantially reduce burglaries in a troubled housing project by working with other city agencies to improve the deteriorating physical condition of the properties and ensure trash removal. ${ }^{198}$ The programs followed in Boston and Chicago also exemplify this cooperative, nonpunitive approach." The "Boston strategy" is built on a broad alliance between police, social service agencies, and leaders of churches, schools, and community groups. ${ }^{2+1}$ After-school programs for youth are a key part of antigang efforts, as are joint police-church leader alliances that target youth identified, through police discussions with community members, as at-risk for joining gangs. In this program, ministers and police jointly visit schools and even homes to dissuade youth from gang activity by warning them of the strict enforcement of criminal sanctions for gang-related crimes and encouraging them to participate in more productive activities. ${ }^{2+1}$ Similarly, in Chicago, individual officers develop friendly relationships with community members that can

ing strategy to a punitive "zero tolerance" policy that hurt police relations with minority communities).

${ }^{1 / 4}$ Ste Livingston, supra note 186, at 575 (illustrating how community policing helped the burglary rate drop by thirty-five percent); Wilson \& Kelling, Making Neighbrilueds Safk, supra note 195, at 46-47 (same).

"'" On Boston's program, see Deborah A. Ramirez et al., Rethinking the CuIture of Professional Policing: Democratic Theory, Police Integrity and a Service-Oriented Community Justice Mlodel of Law Enforcement 11-13 (Sept. 23, 1999) (unpublished manuscript, on file with author). On Chicago's program, see SKOGAN \& HARTNETT, spora note 192; Eig, supra note 192, at 63 ("Chicago's community policing program may be the city's most progressive police reform in years.").

Ste First Saffty, Then Civility, ECONOMIST, May 1, 1999, at 25 [hereinafter First Siffty] ("What makes Boston's crime-fighting different is the willingness of the police to work with other organisations and community groups."); Charles A. Radin, Youth Crime Dotun, but Not Out, BosTON GloBe, Mar. 14, 1999, at B1 (describing the "Boston Strategy" as a "one-two punch involving community groups and law enforcement aimed at getting troublesome youths off the street"); Charles A. Radin \& Daniel Vasquez, City Mobilizes To Stem Gangs' Lure, Boston GLOBE, Mar. 27, 1998, at A1 (discussing Boston's antigang and community policing efforts).

$i^{\prime \prime \prime} S_{t}$ Radin, supra note 200 (noting that police officers supported the initiative because they believed "enforcement alone [would] not solve the city's youth problems or prevent a resurgence in crime"); Radin \& Vasquez, supra note 200 (explaining that "police developed a list of more than 200 at-risk youths" and "teams of ministers and lawenforcement officers began visiting their homes"). Note that this strategy follows Ayres and Braithwaite's model of "benign big guns" for regulators who put persuasion and cooperation in the foreground but keep the backup of punishment clear to offenders. AlRES \& BRATHWAITE, supra note 34, at 49. 
lead to acquiring better information helpful in catching offenders, assuring that witnesses show up to court, and assisting police work with neighborhoods on "pressing community issues such as abandoned vehicles and neglected children." ${ }^{202}$ For example, one Chicago beat officer using the approach reports that she rarely writes traffic tickets. ${ }^{213}$ Due to her knowledge and trust in the community, she arranged for a parole violator that she spotted on the street to be picked up the next day rather than taken to jail immediately. ${ }^{204}$ The officer believes that that level of respect and cooperation accounts not only for why the offender cooperated instead of fleeing, but why gang members on another occasion helped subdue a man who was resisting arrest by punching the officer. ${ }^{205}$

These sorts of strategies exactly parallel the nonpunitive, cooperative, negotiated compliance strategies found increasingly in whitecollar regulation. In both settings, the biggest challenge can be changing the mindset of enforcement officials, agency inspectors, or police officers from punitive sanctioning to cooperative and preventive problem solving that builds trust and mutual respect. ${ }^{21 \%}$ Officers' roles in community policing roughly match the role of "Designated Compliance Officers" in OSHA's Cooperative Compliance Program, who were freed from the usual pressures on inspectors to "write citations and build a case., ${ }^{207}$ Compliance officers instead built cooperative and advisory relationships with regulated firms as part of OSHA's shift to "flexible regulatory enforcement" and away from its traditional approach of frequent citations and fines. ${ }^{208}$ Likewise, these policing strategies recall the EPA's negotiation with firms that violate pollution rules for "supplemental environmental projects" in lieu of sanctions."

\footnotetext{
${ }^{202}$ Eig, supra note 192, at 62.

203 Id. at 63.

${ }^{204} I d$. at 62-63.

205 Id.
}

${ }^{206}$ See id. at 67 ("[T] he ultimate success of community policing still depends on the outcome of a fight for the hearts and minds of police officers.").

${ }^{207}$ REES, supra note 33, at 195; see also id. at 175-218 (describing the Cooperative Compliance Program and Compliance Officers' roles).

${ }^{208}$ See id. at 194-95 (discussing OSHA's attempt to match "regulatory tools" to "regulatory problems").

${ }_{209}$ For the EPA's policy, see EPA Supplemental Environmental Projects Policy, 63 Fed. Reg. 24,796 (May 5, 1998). In all of these contexts, there is a risk of "capture" of regulators by the firms or people they regulate. Police forces risk greater incidence of corruption with officers established in communities. The risk of agency co-optation by firms is well known. See, e.g., AYRes \& BRAITHWAITE, supra note 34, at 54-57, 74 (discussing capture in agency contexts generally); REES, supra note 33, at 236 (noting the 
In addition to these explicitly cooperative, nonpunitive components, community policing sometimes includes harsher strategies, two of the most prominent being antigang loitering ordinances and civil injunctions that declare gang activity a public nuisance. Both are widely used now in several cities, although the most prominent loitering ordinance-Chicago's-was recently declared unconstitutional. ${ }^{210}$ Both of these strategies are more punitive than cooperative. The loitering strategy, and related approaches using juvenile curfews or traditional loitering ordinances, convicts offenders of a low-grade crime. The injunction strategy is more innovative. It declares a particular street gang a public nuisance and enjoins its members from a range of activities, some of which are otherwise legal conduct.

These strategies likewise shift street enforcement a few degrees toward the regulatory enforcement model. Loitering prosecutions are aggressive and, to many offenders, may seem harassing and nitpicking. Because police clearly target their efforts on certain subgroups who are mostly young and minorities, the approach risks aggravating previously existing legitimacy problems. Yet, there is some evidence that the strategy is not widely viewed this way in the communities in which it is employed. ${ }^{211}$ Scholars who advocate the approach and work with or survey community groups where the loitering ordinance has been enforced find broad support for the strategy, even though people there are likely to oppose much harsher enforcement strategies that rely on long prison terms. ${ }^{212}$

These sentiments accord with policy arguments for the strategy that track corporate regulatory approaches more than punitive street crime models. Loitering enforcement is part of a larger ordermaintenance policing regime that supports a social norms strategy for crime prevention. By removing loiterers who signal a strong gang presence in a community, the community reduces the fear and intimidation experienced by residents-social costs of crime borne by

possible dangers of co-optation for OSHA inspectors); Dana, supra note 44, at 1212-14 (providing evidence of underdeterrence supplemental environmental agreements, which may reflect similar problems in the EPA's regulatory scheme).

21" City of Chicago v. Morales, 527 U.S. 41 (1999).

:2I Se' First Safely, supra note 200 (discussing reduced hostility to a police stop-andfrisk policy achieved because " [a] lot of the problem [of hostility] goes [away] if there is mutual respect, if the police explain why the search is being done" (quoting Boston Police Commissioner Paul Evans)).

${ }_{2322}$ Se', e.g., Kahan \& Meares, supra note 186, at 1163 ("Broadly speaking, inner-city minorities support the new community policing ...."); see also Stuntz, supra note 24, at 1797 (noting that survey data of African-American citizens find opposition to "get tough" enforcement policies and a general lack of faith in the criminal justice system). 
indirect victims-and modestly signals that law-abidingness, rather than criminal activity, characterizes the community. Further, despite being punitive, loitering convictions are much less punitive than convictions for more serious crimes. The approach not only reduces the ancillary social costs of criminal enforcement, especially those stemming from long incarceration, but it also mimics Braithwaite's responsive-regulation pyramid model of punishment that urges the least punitive sanctions be applied first-that is, loitering arrests rather than drug arrests. ${ }^{213}$

The public nuisance injunctions, used prominently in California, are justified in the same way. ${ }^{214}$ Despite their civil form, they are undeniably burdensome and punitive on offenders. They substantially infringe liberty interests and raise constitutional questions. ${ }^{215}$ They are, however, at least less punitive than criminal convictions and incarceration would be, and their stigmatic and expressive effects, while not negligible, are also less than criminal sanctions would be. Public nuisance injunctions bear comparison to the severe civil remedies that firms face under regulatory regimes. Civil investigative demands, administrative and civil fines, recordkeeping requirements, and injunctive conditions are substantial burdens and sanctions, even though they are not criminal in form. Industries sometimes complain about such regulation, but offender complaints about those tools probably are not the key source of legitimacy problems for enforcement regimes. Like the gang loiterers who resent ordinance enforcement, offending firms are still encountering the lesser of two harsh responses. Better to incur harsh civil sanctions than harsh criminal ones.

Unlike a social depravity defense, the best community policing strategies provide a feasible way to incorporate knowledge of social norms and influence into criminal justice policy. Rather than ignoring the bad "constitutive luck" of some classes of offenders, community policing, in part, takes rough account of it, shifting some of its resources from harsh punitivism toward strategies that work to revise the social influence generating some of that bad luck, and thus strength-

${ }^{213}$ See AYRES \& BRAITHWAITE, supra note 34, at 35 (laying out the fundamentals of pyramid strategies of responsive regulation); John Braithwaite, Inequality and Republican Criminology, in CRIME AND INEQUALITY 277, 299-302 (John Hagan \& Ruth D. Peterson eds., 1995) (diagramming sanctioning possibilities through which the state can escalate).

See, e.g., People ex rel. Gallo v. Acuna, 929 P.2d 596 (Cal. 1997) (upholding the use of civil public nuisance injunctions against gang members in San Jose, California).

${ }^{215}$ Matthew Mickle Werdegar, Note, Enjoining the Constitution: The Use of Public Nuisance Abatement Injunctions Against Urban Street Gangs, 5I STAN. L. REV. 409 (1999). 
ening prevention and enforcement. In this way, community policing is a type of street criminal justice policy where program directors can put into action a social influence conception in a roughly comparable way to its role in the corporate context. When possible, officials consciously avoid tactics that alienate citizens and engender resistance. Criminal justice policies that reduce social disorder bear some comparison to corporate compliance plans that use social influence and surveillance to reduce criminal acts, while moderating the use of punitive sanctions.

\section{B. Drug Treatment Courts}

Another reform of traditional approaches to street crime is the recent, widespread development of drug courts. ${ }^{210}$ Alongside, and in partial response to, draconian mandatory sentencing rules for drug offenders, state and federal jurisdictions have designed a less punitive, treatment-oriented alternative to imprisonment. Drug courts typically handle nonviolent criminal offenders who, after either pleading guilty or accepting responsibility in some other form, enter a drug treatment program overseen by the courts. Judges and court personnel, in conjunction with treatment providers, closely monitor clients' participation and progress in the programs, which vary in their form, structure, and duration-for example, residential versus outpatient. ${ }^{217}$ Drug courts use an array of remedial devices, from punitive sanctions to various treatment regimes, to respond to client progress or relapse during treatment. Crucially, they typically view relapse not as a failure that terminates treatment and forces offenders back to traditional courts, but as an expected hurdle in a long recovery process that reqires the court to adjust its remedial response. Addicts are expected to relapse, perhaps many times, yet treatment can still succeed.

Note again the similarity of this approach to Ayres's and Braithwaite's responsive regulation for corporate activity. It is contextual, designing different treatment programs for different offenders, and includes a range of possible government responses and sanc-

iil. I rely heavily for my account of drug courts on Michael C. Dorf \& Charles F. Sabel, Drug Treatment Courts and Emergent Experimentalist Government, 53 VAND. L. REV. $831(2000)$.

"Use of the "client" nomenclature in treatment programs, rather than "offender" or "defendant," is itself a sign of a shift away from punitive criminal law. This is comparable to some regulatory contexts, in which firms may be viewed as "providers," "employers," "partners," or simply firms. 
tions. ${ }^{218}$ It fosters and relies on trust, cooperation, and persuasion, but is backed up by monitoring and the threat of punitive sanctions, which are used only when less punitive options have temporarily failed. ${ }^{219}$ It is sensitive to the offender's response to regulation and adjusts regulation according to good measures of efficacy, such as, how well the court's plan works at reducing social harm. ${ }^{220}$ It aims to reintegrate offenders into society rather than shame them in an unproductive, alienating fashion; punishment works within a larger remedial program to build commitment to compliance. ${ }^{221}$

This mix of sanctions and treatment seems to work at retaining clients in treatment better than both traditional criminal courts and noncourt treatment programs. ${ }^{222}$ Note also the conceptual shift that supports the drug court movement. Drug courts reconceptualize both the nature of addiction and a limited, but widespread, form of criminal offending. Instead of viewing drug usage and the related criminal activity stemming from it as a moral failing that deserves criminal condemnation and is appropriately deterred with punitive sanctions, drug courts recognize and respond to the medical, psychological, and social nature of addiction behavior. Without decriminalizing drug usage or even leaving the criminal justice system, drug courts have evolved into flexible bodies comparable to administrative agencies that engage in long-term monitoring of offenders, emphasize cooperative and therapeutic approaches over punitive approaches, greatly reduce the attendant social costs of criminal punishment, and provide more cost-effective use of the public resources addressing criminal misconduct. ${ }^{223}$ In fashioning a flexible, client-sensitive, cost-efficient remedial approach to wrongdoing, drug courts are a street crime ana-

${ }^{218}$ AYRES \& BRAITHWATTE, supra note 34, at 35-38 (positing a pyramid of enforcement activities with increasing punitive power).

${ }^{219}$ See id. at 25-26 ("The trick of successful regulation is to establish a synergy between punishment and persuasion.").

${ }^{220}$ See id. at 35-38 ("Regulatory agencies have maximum capacity to lever cooperation when they can escalate deterrence in a way that is responsive to the degree of uncooperativeness of the firm.").

${ }_{221}$ See id. at 51 (noting the greater importance placed on the "moral educative effects" of regulatory punishment).

${ }^{222}$ See Steven Belenko, Research on Drug Courts: A Critical Review, 1 NAT'L DRUG: CT. INST. REV. 1, 23-24 (1998) ("[D]rug courts generate savings in jail costs[,] ... probational supervision, police overtime and other criminal justice costs... [, as well as] victimization, theft reduction, public assistance and medical claims costs ....").

${ }^{223}$ See Dorf \& Sabel, supra note 216, at 849-50 (detailing review assessments of drug court performance). This is so even though such courts often deal with offenders who have substantial criminal histories. Id. at 850. 
logue to regulatory reforms that replace overly punitive and expensive command-and-control tactics such as those employed at times by OSHA or the EPA.

\section{Therapeutic and Restorative Justice Approaches to Street Crime}

The criminal justice system also utilizes a number of active models for resolving a large set of traditional street crimes through alternatives to adversarial adjudication and punitive sentencing. An array of programs fits this description and goes by various names, including victim-offender mediation, restorative justice, and reparative probation. For brevity, I will focus on only two examples to demonstrate that strategies similar to white-collar regulatory models have proven, if small-scale, track records in street crime policy that could provide a basis for expanding reform efforts.

\section{Victim-Offender Mediation}

Victim-offender mediation ("VOM"), while marginal to the mainstream criminal justice system, now has a quarter-century history in the United States and is found in several hundred local justice systems. ${ }^{2.21}$ These programs typically bring offenders and victims together with a mediator, often after separate, premediation discussions. They focus on allowing the victim to provide input on sanctions and reparations and give her an opportunity to express how the crime has affected her. ${ }^{2: 3}$ A typical case for VOM could be as serious as a felony burglary and property theft; a typical resolution could be an apology and acceptance of responsibility, a restitution agreement, or sanctions normally found in probation, such as community service. ${ }^{226}$ VOM

Set Gordon Bazemore \& Curt Taylor Griffiths, Conferences, Circles, Boards, and Mrdiations: The "New Wrave" of Community Justice Decisionmaking, FED. PROBATION, June 1997, at 25, 26-29 (explaining models of community justice decisionmaking and the ways in which community groups are involved in the sanctioning process); Mark S. Umbreit \& William Bradshaw, Victim Experience of Meeting Adult vs. Juvenile Offenders: $A$ Cross-National Comparison, FED. PROBATION, Dec. 1997, at 33, 33-36 (providing statistical studies of victim responses to "victim-affender reconciliation" programs).

5azemore \& Griffiths, supra note 224, at 29; Umbreit \& Bradshaw, supra note 224, at 33-34; see also id. at 34 (summarizing studies finding high victim satisfaction with VOM processes); id. at 38 (reporting the "high level of overall satisfaction experienced by crime victims who participate in a mediation session with the offender regardless of whether the offender is a juvenile or an adult").

$\therefore$ S'r' Bazemore \& Griffiths, supra note 224, at 25 (giving various examples of the contexts in which VOM has been implemented). VOM is used mostly for property and nonviolent crimes, though it is occasionally employed for serious, violent crimes at a 
sometimes occurs in lieu of prosecution, but it can also be a sentencing substitute after a guilty plea. ${ }^{227}$

The model has two interesting features. One is the similarity, again, to "tripartite" regulation that integrates third parties, such as public interest groups or unions at work sites, into the relationship between a firm and its regulator. Union and worker involvement, for example, was a key to the success of OSHA's Cooperative Compliance Program. ${ }^{228}$ Ayres and Braithwaite argue for "tripartism" as a general model for business regulation both to reduce agency capture and to facilitate mutual understanding among firms or offenders, regulators, and public or victim groups. ${ }^{229}$ That sort of cooperative communication not only frequently leads to mutually agreeable strategies for addressing wrongdoing and social harm, but also "transforms confrontational disputes into accommodative encounters" and facilitates less punitive and less alienating remedies. ${ }^{230}$ The victim's involvement in VOM serves much the same purpose-promoting mutual understanding between victim and offender-which may lessen the victim's desire for punitive sanctions and aid the offender's appreciation of the full social harm she caused. VOM has the potential to provide better, yet less punitive, remedies for clearly culpable wrongdoing.

Second, VOM demonstrates the contingency of culpability judgments and sanctions even for clear cases of crime, particularly those of mid-level seriousness-worse than petty offenses, but not as severe as homicides or large-scale frauds. These mid-level crimes are cases the state is determined to address, rather than decline to charge due to mitigating factors or resource constraints, but for which the state has no easy civil remedy alternative. Unlike many examples of corporate wrongdoing, in which restitution is easy and deterrence fulfilled with fines so that expressive and retributive goals can be abandoned, VOM deals with many offenses in which culpability remains a key issue. Yet, such cases are resolved through VOM in a less punitive way than traditional criminal punishment and with lower social costs; at the same time, both victim interests and the goal of offender reintegration, or at least nonalienation, are better served. Creative innovations like VOM, then, suggest that culpability need not lead to harsh, expressive sanctions, even for traditional street crimes

victim's request. Id. at 27.

${ }^{227}$ Umbreit \& Bradshaw, supra note 224, at 33.

${ }^{228}$ REES, supra note 33 , at $135-38$.

229 AYRES \& BRATTHWAITE, supra note 34, at 98.

230 Id. at $81-100$. 


\section{2. "Survivor-Centered" Domestic Violence Policies}

Prosecution of domestic violence is another realm of street crime that, like drug crime, has shifted substantially to a more traditional, punitive policy in the last two decades. Many states and localities have adopted mandatory arrest and no-drop prosecution policies for domestic violence incidents, mandating the harshest mode of punitive justice even in cases in which the victim opposes prosecution. ${ }^{231}$ Despite such harshness, these policies were adopted with progressive motives. They are in large part the product of a successful campaign by feminists and women's rights advocates against states' long histories of failing to respond to domestic abuse of women. ${ }^{242}$ Despite those motives and the flawed policy this approach replaced, the increasing evidence of the ineffectiveness and social costs of mandatory intervention (accepted increasingly by some women's advocates) demonstrates the inappropriateness of narrowly conceived, punitive criminal justice, even for a classic violent crime such as domestic assault or battery.

Several studies now strongly suggest that mandatory arrest and prosecution policies do not deter abusers but in fact often aggravate patterns of abusive conduct. One study found that the mandatory arrest of offenders with indicia of minimal social support-unemployment, failure to graduate from high school, not being married-actually led to more acts of violence by these offenders than when the police failed to arrest them. While the arrest of more socially integrated offenders-employed, educated, married-led to fewer repeat offenses, a policy of mandatory arrest that is insensitive to these social

$:$ For an overview of current prosecution programs, see LAWRENCE W. SHERILAN eT il., Policing Donestic VIOl.enCe: ExPERnients and Dilemimas 14 (1992) (noting that, as of 1988 , ninety percent of urban police agencies had mandatory or preferred arrest policies); Mary E. Asmus et al., Prosecuting Domestic Abuse Cases in Duluth: Drulloping Effectiv' Prosecution Strategies from Understanding the Dynamics of Abusive Relatims ships, 15 HAMLINE L. REv. 115, 128-29, 135-37, 150-51 (1991) (describing Duluth, Minnesota's influential policy and noting that Duluth requires prosecutors to subpoena all victims, whether cooperative or uncooperative); Naomi R. Cahn, Innovative 1tprouth's to the Prosecution of Domestic Violence Crimes: An Overview, in DOMESTIC VIOL InCE: The Changing Criminal Justice Response 161 (Eve S. Buzawa \& Carl G. Buxawa eds., 1992) (stating that jurisdictions with aggressive or no-drop policies include Alexandria, Virginia; Baltimore; Brooklyn; Denver; the District of Columbia; Duluth; King County, Washington; Los Angeles; San Diego; and San Francisco).

S't' grnerally Cheryl Hanna, No Right to Choose: Mandated Victim Participation in Domexic V'olenct Prostcutions, 109 HARV. L. REv. 1849 (1996) (describing feminist activism and theory in support of no-drop domestic violence policies and endorsing those pulicies on feminist grounds as the best among imperfect options). 
dynamics can aggravate domestic violence. ${ }^{233}$ One survey of prosecution programs found women who file charges in jurisdictions that allow them to drop charges face a lower risk of subsequent abuse than women in no-drop jurisdictions. ${ }^{234}$ A third study found no effect on abuser recidivism from prosecution; repeat offending was unaffected by whether a case was not charged, was dismissed, or was prosecuted. ${ }^{235}$ While these studies are not enough to refute no-drop policies completely, they document exactly the sort of perverse effects that administrative regulation has recognized in corporate contexts. Harsh punitivism-raising the "price" of crime-does not necessarily yield the response deterrence analysis suggests. It can engender resistance and resentment that combine with social capital deficits to aggravate rather than alleviate crime.

Moreover, based on extensive clinical psychological evidence, Linda Mills has recently argued that mandatory intervention policies often result in state actors replicating the rejection, degradation, and social isolation that abuse victims suffer from their abusers. ${ }^{236}$ Among other responses, state actors often subtly blame victims for not resisting abuse and respond to victims' uncooperative, fragile, or indecisive demeanors with paternalistic hostility. These responses may stem, Mills suggests, from officials' own frustration with having little power to remedy the violence they confront in their work. ${ }^{287}$ Without summarizing Mills's extensive argument and literature survey here, she proposes as a response to the emotional trauma women suffer in mandatory prosecution locales a "survivor-centered model" of law enforcement for domestic violence. ${ }^{238}$ Under this proposal, rather than dictating to victims that prosecution of abusers is the only option, offi-

${ }^{233}$ See SHERMAN ET AL., supra note 231, at 152-53, 160-64 (theorizing that some abusers want to demonstrate that they are not deterred), discussed in Linda G. Mills, Killing Her Softly: Intimate Abuse and the Violence of State Intervention, 113 HARV. L. REV. 550, 565-66 (1999) ("Indeed, mandatory arrest may actually increase the incidence of violence in some battered women's lives.").

${ }^{234}$ David A. Ford \& Mary Jean Regoli, The Criminal Prosecution of Wife Assaulters: Process, Problems and Effects, in LEGAL RESPONSES TO WIFE ASSAULT: CURRENT TRENDS and Evaluation 127, 144, 151-57 (N. Zoe Hilton ed., 1993), discussed in Mills, supra note 233 , at 567 .

${ }^{235}$ Robert C. Davis et al., The Deterrent Effect of Prosecuting Domestic Violence Misdemeanors, 44 CRIME \& DELINQ. 434, 441-42 (1998) ("We found no evidence that prosecution outcomes affected the likelihood of recidivism in domestic violence misdemeanor cases."), discussed in Mills, supra note 233, at 567-68.

${ }^{236}$ Mills, supra note 233 , at $582-86$.

Id. at $570-73,582-86$.

${ }^{238} I d$. at $596-609$. 
cials work in cooperative and supportive ways with victims, with a better understanding of their psychological and social predicaments, to allow women to choose prosecution or alternatives with minimal intimidation from abusers. In this model, officials acknowledge women's complicated ties with abusers as spouses, parents of their children, and income providers; recognize religious and cultural beliefs that discourage or stigmatize separation; treat victims with respect that they often do not receive in personal relations elsewhere; reassure them through help in planning with safe house or social support services; and present prosecution as one of several options that may be appropriate in the victim's case. The officials offer alternatives, including counseling services for the victim and the batterer and family mediation services to repair family relationships that can then support the victim. In this way, the model serves the original feminist goal of supporting women and taking domestic violence seriously while minimizing the substantial downsides of no-drop policies.

The point is that punitive justice approaches, here as elsewhere, may impose high social costs on victims and social groups and ill serve key goals such as reducing future wrongdoing. While prosecution is fully justified as an expressive act and a retributive judgment, the larger balance of social goals and contextual factors may call for a less punitive and more regulatory, cooperative, and context-sensitive response. The lessons from white-collar enforcement work as well with some violent crimes, like domestic abuse, as they do with nonviolent drug crimes or "quality of life" misdemeanors.

\section{Conclusion}

These examples, one may notice, represent a broad slice of the criminal justice system. Drug courts address the single largest category of crimes that fill contemporary court dockets, though reforms target mainly users, not dealers. ${ }^{239}$ Similarly, violence among intimates is a large part of violent crime, and property offenses among neighbors, the typical case for victim mediation, is a large part of property crime. ${ }^{2+4}$ The range of strategies that make up community policing

${ }^{2,44}$ Ko Crime $\mathcal{F}^{\circ}$ Justice Facts, supra note 77.

" BuREAU OF JUSTICE STATISTICS, U.S. DEP'T OF JUSTICE, CRIMINAL VICTIMIZATION IN THE UNITED STATES, 1999 STATISTICAL TABLES, at tbl. 37 (1991), http://www.ojp.usdoj.gov/bjs/pub/pdf/crus99.pdf [hereinafter 1999 STATISTICAL TABLES] (documenting that more than half of personal crimes of violence involve nonstrangers); Press Release, U.S. Department of Justice, Concern About Neighborhood Crime Doubles Among Black Households (June 19, 1994), 
can affect a broad range of street crime; advocates claim it plays a role in the reduction of rates for homicide and other serious crimes. ${ }^{211}$ In short, while punitive justice with a retributive function always has a role in criminal justice, much of the street crime justice system can be reformed with insights from social influence and costs research, development of civil alternatives, and renegotiation of civil and criminal strategies in ways roughly comparable to white-collar contexts. We can build a civil, regulatory, less punitive alternative to current street crime enforcement that comes much closer to matching the scope of the one that exists for corporate activity.

\section{CONCLUSION}

The barrier to this transformation is not primarily differences in offenders or lack of potential alternatives. The hurdle is largely in the ideological infrastructure through which we build, practice, and assess criminal and regulatory justice. Whether or not labeling theory-the idea that the label of one as a deviant furthers one's self-identification as a deviant ${ }^{242}$-explains much about causes of crime, an analogous effect works on public perceptions. Enforcement practices consistently address street crime as the most culpable wrongdoing and white-collar crime as readily amenable to civil remedies. That practice helps to further entrench views of street offenders as distinctive and more blameworthy than other wrongdoers.

Even though some conduct merits the criminal law's moral condemnation, other considerations intrude. Society wants several things from legal responses to wrongdoing: deterrence, prevention, restitution, acceptance of responsibility, minimal social costs, and minimal administrative costs. Other mechanisms besides criminal conviction can get us there. Those goals not only sometimes conflict with judging culpability, but they also mediate our determinations of culpability

http://www.ojp.usdoj.gov/bjs/pub/press/can.pr ("Many convicted offenders report committing crimes near where they lived. For example, the BJS's 1991 survey of state prison inmates disclosed that 43 percent of prisoners were serving time for offenses committed in their own neighborhoods. This included 45 percent of violent offenders and 52 percent of drug offenders."); see also 1999 STATISTICAL TABLES, supra, at tbls. 3334 (documenting the number of family violence crimes by type of relationship).

${ }^{241}$ See Harcourt, supra note 197 , at 292-93 (summarizing sources for this assertion including GEORGE KELLING \& CATHERINE M. COLES, FIXING BROKEN WINDOWS: RESTORING ORDER AND REDUCING CRIME IN OUR COMMUNITIES 24 (1996); Wesley G.

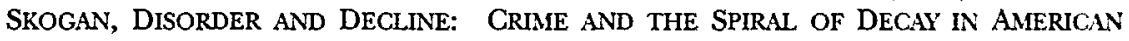
NEIGHBORHOODS $75(1990)$ ).

${ }^{242}$ See JOHN BRAITHWAITE, CRIME, SHAME AND RENTEGRATION 16-21 (1989) (summarizing labeling theory, but doubting its explanatory power). 
itself. Blameworthy conduct need not be dealt with through criminal law's unique condemnation. The process of prioritizing this mix of the policy goals is a political and ideological one. It is political in the basic sense that powerful groups can adjust the mix to their favor; corporate interests have greater ability to influence legislative and executive policymaking toward cooperative regulation and away from punitive justice. It is political, however, in the broader sense that the practices we choose among criminal law and its alternatives shape and reflect our culture, identity, and social relations.

The contingency of criminal liability has distributional consequences as well. We distribute culpability unevenly across the spectrum of wrongdoers. Street offenders incur punitive blame disproportionately, which creates social identities that exaggerate culpability relative to white-collar wrongdoers. Despite explicit conduct and harm, crime is always a socially constructed notion. Views of wrongdoing and culpability vary over time and context so that injurious acts that once were damnum absque injuria become malum prohibitum and even malum in se offenses. ${ }^{23}$ We use many criteria in charging and enforcement decisions to determine real culpability beyond elements of an offense. Our social judgments of when injurious acts become zrongdoing, and wrongdoing becomes culpable, hinge on contextual and ideological influences.

That was a key part of Sutherland's arguments half a century ago about white-collar wrongdoing-we let class bias mislead us into treating corporate wrongdoing nonculpably. Sutherland urged that we respond to white-collar wrongdoing with more criminal law. ${ }^{244}$ That idea may have had some merit half a century ago. While current regulation of white-collar wrongdoing now includes a large array of criminal sanctions, it remains appropriately dominated by noncriminal remedies. White-collar policy is approaching about as good a civil-criminal mix of sanctions and compliance strategies as we are likely to get in

For discussions of how criminal law shapes preferences, see Kenneth G. DauSchmidt, An Eronomic Analysis of Criminal Law as a Preference-Shaping Polig, 1990 DUKE L.J. 1; Kahan \& Posner, supra note 143, at 376-78.

SUTHERLAYV, supra note 123. This remains a prominent position today in criminological literature. See, e.g., HAINES, supra note 18, at 4 ("Following Sutherland, the most consistent demand [among scholars through the 1990s] was for use of the criminal law."); Kitty Calavita \& Henry N. Pontell, The State and White-Collar Crime: Saving the Saving and Loans, 28 L. \& SOC'Y REV. 297, 298 (1994) (noting "a vast literature" following Sutherland's work); Celia Wells, The Decline and Rise of English Murder: Corpowt Crim and Individual Responsibility, 1988 CRM. L. REV. 788 (advocating broader criminal liability for corporate wrongdoing). 
the near future. At minimum, it is much better than our mix for street wrongdoing. White-collar criminal sanctions provide "big guns" for the worst wrongdoing that deserves moral blame, while a broad range of creative, and sometimes harsh, civil sanctions predominate. Civil sanctions serve prevention and restitution goals better than criminal law and give more attention to punishment's social costs, effects on social norms, and backlash effects. We have nothing like that productive range of strategies for street crime, and as a result, we suffer much higher social costs, less effective prevention, and excessive imposition of moral blame.

Thus, it is not that corporate crime should be handled more like street crime. Rather, street crime should be addressed more like corporate crime. The corporate crime model points toward ways to minimize the role of criminal law generally, especially with respect to utilitarian functions. ${ }^{245}$ Given its high ancillary costs, we could reserve criminal law for where we need not only a utilitarian tool, but also an expressive or retributive one. That shift would take greater advantage of knowledge of social norms and structural restraints, and it would serve interests in distributive equity. However just retributive and expressive goals are in theory, the fact is that punishment based on just deserts is applied inequitably. Punishments that express culpability are much more frequently applied to the poor-to street offenders. ${ }^{2 i n}$ White-collar offenders face less expressive, condemnatory sanctions that mitigate, rather than aggravate, views that their wrongdoing is morally blameworthy and that impose fewer social costs. Within its universe of regulatory tools and sanctions, corporate regulation is relatively stingy with criminal judgments. For distributive equity and more effective policy, we should also look to that model for regulation of street crime.

245 Both white-collar and street sectors are overcriminalized. See Stuntz, supra note 137, at 15-19 (describing why legisiatures allow overcriminalization). But for street crime, we actually use criminal statutes much more than in white-collar settings. Overcriminalization is a problem of active enforcement practice in the former context, but largely only a theoretical problem of statutory breadth in the latter.

${ }^{246}$ Cf. Braithwaite, supra note 213, at 280 (arguing that a desert-based theory ends up, in practice, imposing substantially harsher penalties on the poor than on the rich and, ironically, a minimalist punishment structure-one that imposes punishment "as low as we can [make] it without clear evidence that crime has increased as a result"turns out to be more equitable). 